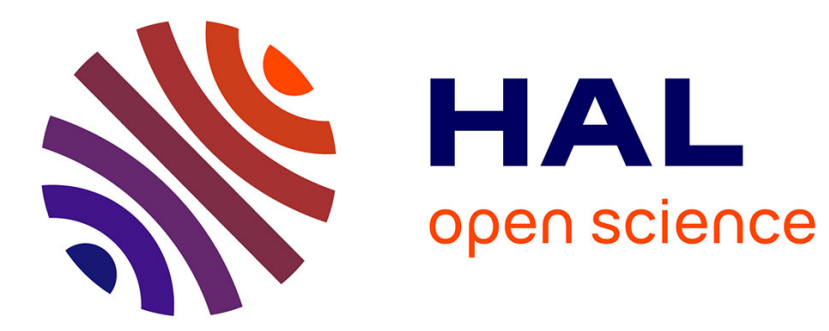

\title{
Un florilège biblique mis sous le nom de Cyprien de Carthage: l'Exhortatio de paenitentia (CPL 65)
}

Laetitia Ciccolini

\section{To cite this version:}

Laetitia Ciccolini. Un florilège biblique mis sous le nom de Cyprien de Carthage : l'Exhortatio de paenitentia (CPL 65). Recherches augustiniennes et patristiques, 2011, 36, pp.89-138. halshs-01452417

\section{HAL Id: halshs-01452417 https://shs.hal.science/halshs-01452417}

Submitted on 8 Mar 2020

HAL is a multi-disciplinary open access archive for the deposit and dissemination of scientific research documents, whether they are published or not. The documents may come from teaching and research institutions in France or abroad, or from public or private research centers.
L'archive ouverte pluridisciplinaire $\mathbf{H A L}$, est destinée au dépôt et à la diffusion de documents scientifiques de niveau recherche, publiés ou non, émanant des établissements d'enseignement et de recherche français ou étrangers, des laboratoires publics ou privés. 
Recherches augustiniennes et patristiques, 36 (2011), 89-138.

\section{Un florilège biblique mis sous le nom de Cyprien de Carthage: l'Exhortatio de paenitentia $(C P L 65)^{1}$}

L'Exhortatio de paenitentia (désormais Paen) est un court florilège biblique sur le thème de la conversion du cœur et de la pénitence, attribué dans les manuscrits à Cyprien de Carthage. Son principal intérêt est d'offrir un texte biblique non vulgate et souvent original. Manuels et répertoires le rangent parmi les écrits pseudépigraphes et s'accordent à le dater de la fin du IVe s. ou du début du V $\mathrm{V}^{\mathrm{e}} \mathrm{s}$. et à situer son origine en Afrique ${ }^{2}$. Giovanni Grisostomo Trombelli le découvrit dans l'un des deux "Cyprien» que possédait le monastère San Salvatore de Bologne et le publia en 1751, en le présentant comme un texte authentique de Cyprien de Carthage écrit contre Novatien ${ }^{3}$. L'édition de Trombelli fut reprise en 1844 dans le volume de la Patrologie Latine des œuvres de Cyprien, mais le texte est cette fois répertorié parmi les écrits "douteux»" ${ }^{4}$. Cette réimpression reste l'édition la plus accessible, mais il existe deux autres éditions de la fin du XIXe s. : celle de

1. Je remercie pour leurs conseils et leur aide Pierre Petitmengin et les participants à l'atelier médio-latin du 21 mars 2009 auxquels j'ai soumis un premier état de ce travail.

2. CPL 65; CPPM, t. II, 3231; R. GRYSON, Répertoire général des auteurs ecclésiastiques latins de l'Antiquité et du haut Moyen Âge, I, Freiburg, 2007, p. 438. Cf. aussi plus anciennement A. HARNACK, Geschichte der altchristlichen Literatur bis Eusebius, II, 2. Die Chronologie der Literatur von Irenäus bis Eusebius, Leipzig, 1904, p. 386-387, et M. SCHANZ, C. Hosius et G. KRÜGER, Geschichte der Römische Litteratur, III. Die Zeit von Hadrian 117 bis aufConstantin, München, 1922, p. 382. Ces auteurs s'opposent à P. MONCEAUX, Histoire littéraire de l'Afrique chrétienne, II. Saint Cyprien et son temps, Paris, 1902, p. 86-87, qui voit dans Paen l'œuvre d'un contemporain de Cyprien.

3. Veterum Patrum Latinorum opuscula nunquam antehac edita. Anecdotorum a Canonicis Regularibus S. Salvatoris evulgatorum. Tom. II, pars I, Bononiae, 1751: apud Hieronymum Corciolani et H.H. Colli, p. 1-32.

4. Patrologie Latine, t. 4, Paris, 1844, c. 1149-1190. Paen est cité parmi les opera dubia, c. $809-810$. 
C. Wunderer qui date de 1889 et celle d'A. Miodoński parue en $1894^{5}$. Wunderer accompagne son édition d'une brève étude où il montre l'inauthenticité du florilège et propose d'y voir l'œuvre d'un Africain de la fin du rve s. ou du début du $V^{e}$ s., compilée pour lutter contre les Novatiens. Ces conclusions, qui adaptent à une datation plus basse la thèse de Trombelli, sont adoptées par Miodoński. Si la bibliographie se résume à ces trois éditions ${ }^{6}$, le témoignage de Paen est régulièrement allégué dans le cadre des travaux sur le texte biblique vieux latin, qu'il s'agisse d'éditions ${ }^{7}$ ou d'études ponctuelles ${ }^{8}$. Il est donc essentiel de pouvoir disposer d'une édition fiable et d'un aperçu de l'histoire de ce petit texte afin d'évaluer correctement son apport.

Les travaux menés depuis la fin du XIX ${ }^{e} s$. sur la tradition manuscrite des œuvres de Cyprien de Carthage, ainsi que la publication de nouveaux catalogues de manuscrits permettent d'augmenter sensiblement la liste des témoins de Paen. Wunderer n'a pas identifié le manuscrit utilisé par Trombelli, mais il s'est servi de deux manuscrits très proches, $A$ (Augsburg, Staats- und Stadtsbibliothek, Fol. Cod. 65, milieu du XV s.) et $M$ (Madrid, Bibl. Nac. 5569, XV s. [1416]). Miodoński ajoute un témoin plus ancien, le manuscrit $P$ (Paris, Bibl. de l'Arsenal $550, \mathrm{XIII}^{\mathrm{e}} \mathrm{s}$.). À la suite de son étude sur la tradition des lettres de Cyprien, $\mathrm{H}$. von Soden consacre un appendice aux écrits pseudépigraphes, qui permet de porter à huit le nombre de manuscrits (il ajoute cinq manuscrits du XV $\left.\mathrm{Xv}^{\mathrm{e}} \mathrm{s}\right)^{9}$. Aujourd'hui, on peut dénombrer dix-sept témoins du texte: aux trois manuscrits déjà utilisés par Wunderer et Miodoński s'ajoutent douze manuscrits du XV s. et deux du XII $\mathrm{s}$. L'examen de l'histoire du texte nous a conduit à proposer une nouvelle édition,

5. C. WUNDERER, Bruchstücke einer afrikanischen Bibelübersetzung in der pseudocyprianischen Schrift Exhortatio de paenitentia neue bearbeitet, Erlangen, 1889; A. MIODOŃSKI, «Incerti auctoris Exhortatio de paenitentia», Rozprawy Akademii Umiejętności. Wydział Filologiczny, 2, 5, 1894, p. 125-134.

6. Il existe aussi une traduction anglaise par $\mathrm{E}$. Wallis dans The Ante-Nicene Fathers. Translations of the Writings of the Fathers down to A. D. 325, A. Roberts and J. Donaldson editors. American reprint of the Edinburgh edition, revised and chronologically arranged with brief prefaces and occasional notes by A. Cleveland Coxe, V. Fathers of the Third Century: Hippolytus, Cyprian, Caius, Novatian, Buffalo-New York, 1887 (reprint Grand Rapids, Michigan, 1986), p. 592-595.

7. Dans l'édition de la Vetus Latina d'Isaïe par exemple, Vetus Latina. Die Reste der altlateinischen Bibel, 12. Esaias, R. Gryson (éd.), Freiburg, 1987-1997, Paen sert occasionnellement de lemme pour $\mathbf{C}$, la forme africaine récente du texte.

8. M. StENZEL, «Die Konstanzer und St. Galler Fragmente zum altlateinischen Dodekapropheton», Sacris erudiri, 5, 1953, p. 27-85, consacre un développement à Paen.

9. H. VON SODEN, Die cyprianische Briefsammlung. Geschichte ihrer Entstehung und Überlieferung, Leipzig, 1904, p. 228-229. Sa liste comporte un manuscrit aujourd'hui disparu, Venezia, San Michele di Murano fol. $28, \mathrm{XV}^{\mathrm{e}} \mathrm{s}$., désigné sous le sigle 545 . On rectifiera les points suivants : le manuscrit collationné par Miodoński est conservé à la bibliothèque de l'Arsenal et non à la Mazarine; le manuscrit de Munich, BSB, $\mathrm{Clm} 3586, \mathrm{XV}^{\mathrm{e}} \mathrm{s}$. ne contient pas Paen; Trombelli a édité le texte à partir d'un seul manuscrit de Bologne. 
sur des bases un peu différentes de celles de nos prédécesseurs, et à reposer la question de la datation, de la localisation et de l'objet de Paen à la lumière de ces données nouvelles.

\section{I. - PRÉSentation du teXTE}

Le premier point qui retient l'attention est la structure du florilège. Paen est constitué de quarante-cinq extraits de longueur variable - un seul verset pour les $\mathrm{n}^{\text {os }} 3$ et 19 , une dizaine pour le $\mathrm{n}^{\circ} 44-$, représentant au total cent quatre versets scripturaires. Les citations ne sont pas commentées; elles sont introduites très sobrement, par l'indication du livre biblique ou item illic ${ }^{10}$. Elles sont regroupées sous une rubrique unique qui en donne l'orientation: tous les péchés peuvent être remis moyennant une pénitence sincère et la conversion du cœur. Sous le titre des manuscrits exhortatio de paenitentia, on ne trouve donc qu'un seul dossier scripturaire, réuni pour étayer, de manière assez détaillée, l'idée énoncée dans le titre-sommaire qui précède. Paen ne semble pas être un texte autonome; on songe plutôt à une section particulière d'un florilège thématique de plus grande ampleur, analogue au chapitre De paenitentia $\left(\mathrm{n}^{\circ} 23\right)$ du Speculum pseudo-augustinien ${ }^{11}$.

Le contenu biblique appelle également une remarque. Le recueil est organisé : il débute par une citation du Psaume 88 et s'achève avec un verset de l'Apocalypse. Malgré quelques entorses, les extraits sont reproduits selon l'ordre des livres d'une Bible ${ }^{12}$ :

- Psaumes (un seul extrait)

- les quatre Grands Prophètes: Isaïe, Jérémie (suivi des Lamentations, attribuées également à Jérémie), Ézéchiel, Daniel

- les Petits Prophètes: Michée, Sophonie, Zacharie et Osée

- l'Ecclésiastique

- les Actes des apôtres (un extrait)

- Épîtres pauliniennes: la seconde Épître aux Corinthiens, la seconde Épître à Timothée

- 1'Apocalypse

10. La seule entorse est l'ajout de de hoc ipso pour le $\mathrm{n}^{\circ} 41$.

11. Le Speculum pseudo-augustinien offre des chapitres dont la longueur est comparable à celle de Paen et qui présentent les citations en suivant l'ordre des livres d'une Bible. La section De paenitentia comporte trente-huit extraits, qui ne recoupent qu'en partie ceux de Paen. Le Speculum ou les florilèges de Cyprien montrent que la proposition infinitive est l'une des formes syntaxiques habituelles que prennent les titres des différentes sections.

12. Une citation de Jérémie figure cependant dans l'ensemble «Isaie». Au sein de chaque ensemble représenté par plus de deux citations (Is, $\mathrm{Jr}, \mathrm{Ez}, 2 \mathrm{Co}$ ), on observe également des entorses dans l'ordre des versets. 
Paen semble surtout structuré autour de deux ensembles: les prophètes (trentecinq extraits, représentant soixante-douze versets) et les Épîtres pauliniennes (cinq extraits, représentant dix-sept versets). Le verbe conuerto apparait comme le mot clef qui justifie la sélection d'une grande partie des citations vétéro-testamentaires ${ }^{13}$; paenitentia est commun à presque toutes les citations néo-testamentaires. L'absence de tout extrait des Évangiles est frappante, tout comme le fait qu'il n'y ait aucune citation avant le v. 31 du Psaume 88. On peut donc se demander si le dossier, tel qu'il figure dans les manuscrits, est complet: a-t-on l'intégralité du dossier sur la pénitence - où étaient délibérément privilégiés les prophètes et les extraits pauliniens - ou celui-ci était-il à l'origine plus fourni ? La structure d'ensemble tout comme le choix des citations bibliques conduit donc à s'interroger sur la nature du texte transmis. Tenter de répondre à cette question impose tout d'abord d'examiner l'histoire du texte telle que les données conservées permettent de la reconstituer.

\section{II. - UN DOSSIER MIS EN CIRCULATION PAR LES CISTERCIENS}

\section{A. Les témoins manuscrits}

L'augmentation du nombre de témoins éclaire sous un jour nouveau l'histoire du texte. Paen est transmis par des manuscrits récents, qui s'échelonnent du XII au $X V I^{e} s$. Sur la base de leur contenu et de leur date, on peut les répartir en deux groupes d'inégale importance pour l'établissement du texte.

\section{1) Les manuscrits cisterciens et $\mathrm{P}$}

Les plus anciens témoins sont deux manuscrits cisterciens où Paen figure dans une collection patristique sur la pénitence et la confession.

1. København, Det Kongelige Bibliotek, Ny. Kgl. S. $2740,4^{\circ}, 3^{\mathrm{e}}$ quart du XII $\mathrm{s}$. (sigle $G$ ), f. $5 \mathrm{v}-10 \mathrm{r}$

Origine: Pontigny

Bibl.: E. JøRGENSEN, Catalogus Codicum Latinorum Medii Aui Bibliothecae Regiae Hafniensis, Hafniae, 1926, p. 152-154; M. PEYRAFORT-HuIN, La bibliothèque médiévale de l'abbaye de Pontigny (XII ${ }^{e}$ XIX ${ }^{e}$ s.). Histoire, inventaires anciens, manuscrits, Paris, 2001, p. 256, 519-521.

2. Paris, BnF, lat. 18072 , ca $1155-1165$ (sigle $H$ ), f. 21 v-26r Origine: Chaalis

Bibl.: M. PEYRAFORT-HUN, La bibliothèque médiévale de l'abbaye de Pontigny, p. 102, n. $18 ; 256$, n. $151 ; 520$, n. 308; A. BONDÉELlE-SOUCHER et P. STIRNEMANN, «Vers une reconstitution de la bibliothèque ancienne de l'abbaye de Chaalis: inventaires et manuscrits retrouvés », Parua pro magnis munera. Études de littérature tardo-antique et médiévale offertes à François Dolbeau par ses élèves, M. Goullet (éd.), Turnhout, 2009, p. 18, 26, 32, 33, 60.

13. On ajoutera les citations où figure un verbe de la même famille, reuerto ( $\mathrm{n}^{\circ} 14$ ) ou même auerto $a$ (nos 4 et 25 ). 
Les deux manuscrits ont le même contenu ${ }^{14}$ :

1. $<$ Ps. $>>$ Hier., Liber de ortu beatae Mariae et infantia Saluatoris (Bibliotheca Hieronymiana Manuscripta, t. $3 \mathrm{~B}, \mathrm{n}^{\circ} 670$ ). Le texte ne figure plus dans $G$, qui est mutilé.

2. Aug., De patientia (CPL 308). Seules les deux dernières lignes subsistent dans $G$.

3. $<$ Ps. $>$ Aug., De agenda paenitentia (= Caes.-Arel., Sermo 65; CPPM, t. I A, 1043)

4. Ioh.-Chrysost, De confessione (= Collectio Escurialensis, hom. 27;CPL 926)

5. Paen

6. Ephraem lat., De munditia animae (= De die iudicit et de resurrectione; CPL 1143, I; CPG 4080)

7. $<$ Ps. $>$ Ioh.-Chrysost., De paenitentia (CPPM, t. I A, 2353)

8. $<$ Ps. $\rightarrow$ Isid., Lamentatio (CPL 1227)

9. suivi, sans nom d'auteur ni titre de CPL 1533 (Sisbertus Toletanus, Lamentum paenitentiae)

10. suivi, sans nom d'auteur ni titre de CPL 1228 (Ps.-Isid., Oratio pro correptione uitae)

11. Iust., Edictum rectae fidei confessionem continens et refutationem haeresium quae aduersantur catholicae Dei ecclesiae (CPG 6885)

12. Aug., De Prouerbiis Salomonis (= Sermo 37)

13. $<$ Ps. $>$ Aug., De quattuor virtutibus caritatis (= Quoduultdeus ; CPL 412a)

14. $<$ Ps. $>$ Aug., De tempore barbarico (= Quoduultdeus; CPL 411)

15. $<$ Ps.- $>$ Anast., Ad monachos (= Ps.-Athan., De obseruationibus monachorum; CPL 1155)

16. $<$ Ps. $>$ Caes.-Arel., Ad monachos, numero decem (=Ps.-Eus.-Gall.; CPL 966 ; CPPM, t. I B, 4590-4600, 4653-4662)

17. $<$ Ps. $>$ Faust.-R., Ad monachos (CPL 971 ; CPPM, t. I B, 4731)

18. $<$ Ps. $>$ Faust.-R., Ad monachos (= Caes.-Arel., Sermo 235; CPPM, t. I B, 4732)

19. Sans nom d'auteur, Sermo de paenitentia (= Paulinus Burdigalensis ? CPL 981 ; CPPM, t. I B, 4743)

20. Aug., In libro De ciuitate Dei, XXII, extraits des chap. 29-30

La collection a circulé plus largement en milieu cistercien: un corpus analogue se trouvait en effet dans la bibliothèque de Vauluisant au début du XVI ${ }^{\mathrm{c}} \mathrm{s}$. sous la cote XXII/Q: Libri quattuor dialogorum S. Gregorii, Hieronimi de ortu semper uirginis Mariae, $B$. Augustini de patientia, homelia eiusdem de agenda paenitentia, sermo B. Ioannis Chrisostomi de confessione, exhortatio B. Cipriani de paenitentia, sermo $S$. Augustini de quattuor uirtutibus charitatis, eiusdem sermo de tempore lubrico, sermo Fausti episcopi ad monachos, liber Senecae de quattuor uirtutibus principalibus, uita S. Mariae Agyptiacae metrice scripta15. La collection est précédée des quatre livres des Dialogi de Grégoire le Grand et s'achève avec la Formula honestae uitae de Martin de Braga et une vie métrique de Marie l'Égyptienne. La notice ne reprend pas tous les titres des manuscrits conservés, sans que l'on puisse dire si la série était tronquée ou si la notice est simplement sélective; Paen est en tout cas explicitement mentionné.

14. Les abréviations sont celle du dictionnaire d'A. BLAISE, Dictionnaire latin-français des auteurs chrétiens, Turnhout, 1954.

15. Je remercie Pierre Petitmengin de m'avoir communiqué cette information. Sur la bibliothèque de Vauluisant, on se reportera à F. BOUGARD, P. PETTTMENGIN et al., La bibliothèque de l'abbaye cistercienne de Vauluisant. Histoire et inventaires, Paris, 2011. 
Paen figure aussi dans un manuscrit $\mathrm{du} \mathrm{xH}^{\mathrm{e}} \mathrm{s}$, au milieu de textes médiévaux:

3. Paris, Bibl. de l'Arsenal 550, Xmre s. (sigle $P$ ), f. 128va-130ra

Provenance: acheté par le couvent des Grands Augustins en 1338.

Bibl.: H. MARTIN, Catalogue des manuscrits de la bibliothèque de l'Arsenal, t. 1, Paris, 1885 , p. 413-414; J. CHÂTILLON, «Un sermon du XI" siècle en quête d'auteur: Richard de Saint-Victor, Geoffroy de Melrose, Geoffroy d'Auxerre ou Aelred de Rielvaux », Recherches augustiniennes, 20, 1985, p. 175; ID., Trois opuscules spirituels de Richard de Saint-Victor. Textes inédits accompagnés d'études critiques et de notes, Paris, 1986, p. 35-36, 88-90.

Le manuscrit contient les textes suivants:

1. Richard de Saint-Victor, De exterminatione mali et promotione boni

2. Richard de Saint-Victor, De uera dilectione et perfecta mansuetudine

3. $<$ Richard de Saint-Victor $>$, Carbonum et cinerum reliquiis

4. Sermo in natali beati Gregorii papae (= Geoffroy d'Auxerre? Aelred de Rielvaux ?)

5. $<$ Richard de Saint-Victor $>$, Causam quam nesciebam

6. $<$ Ps. $\rightarrow>$ Richard de Saint-Victor, Sermo de euangelio. Cum esset Ihesus annorum duodecim (= Aelred de Rielvaux, De Iesu puero duodenni)

7. André de Saint-Victor, Obiectiones (sur Is 7, 14-16); <Richard de Saint-Victor>, De Emmanuele

8. $<$ Aelred de Rielvaux $>$, Speculum caritatis

9. $<$ Hugues de Fouilloy>, De nuptiis

10. <Hugues de Fouilloy>, De fonte compunctionis

11. <Hugues de Fouilloy>, De nuptiis spiritualibus

12. <Hugues de Fouilloy>, De medicina animae

13. <Hugues de Fouilloy>, De auibus

14. Paen

15. Chrétien de la Sauve-Majeure, Vita beati Geraldi primi abbatis Siluae Maioris (BHL 3418)

16. $<$ Ps. $->$ Aug., De quattuor uirtutibus caritatis (= Quoduultdeus; CPL 412a)

17. Aug., In Iohannis epistulam ad Parthos tractatus (CPL 279)

18. Aug., De perfectione iustitiae horninis (CPL 347)

19. <Ps. $>>$ Aug., De assumptione beatissimae uirginis Mariae (= Guillaume de Saint-Thierry? CPPM, t. II, 161)

L'origine du manuscrit est inconnue. On remarque cependant qu'il comporte des textes, comme le De auibus ${ }^{16}$, en faveur chez les cisterciens.

\section{2) Les recentiores}

Paen figure également dans quatorze manuscrits tardifs $\left(\mathrm{XV}^{\mathrm{e}} \mathrm{s}\right.$. et $\mathrm{XVI} \mathrm{I}^{\mathrm{e}} \mathrm{s}$ ), qui transmettent les œuvres de Cyprien de Carthage. Dans treize témoins, Paen se lit dans un appendice d'écrits authentiques et inauthentiques qui vient compléter un important corpus, très diffusé en Italie ${ }^{17}$.

16. Voir sur ce point B. VAN DEN ABEELE, «Trente et un nouveaux manuscrits de l'Aviarium: regard sur la diffusion de l'œuvre d'Hugues de Fouilloy », Scriptorium, 57, 2003, p. 270.

17. Pour la bibliographie de ces manuscrits, nous nous limitons à quelques données sélectives. Sur leur place dans la tradition manuscrite de Cyprien, on se reportera notamment à M. BÉVENOT, The Tradition of Manuscripts. A Study in the Transmission of St. Cyprian's Treatises, Oxford, 
4. Augsburg, Staats- und Stadtsbibliothek, Fol. Cod. 65, milieu du XV s. (sigle $A$ ), f. $216 \mathrm{v}-219 \mathrm{r}$

Origine: Italie du Nord

Provenance: abbaye de Plankstetten

Bibl.: H. SpILLING, Die Handschriften der Staats- und Stadtbibliothek Augsburg $2^{\circ}$ Cod 1 100, Wiesbaden, 1978, p. 95-98; M. MARIN, «Problemi di ecdotica ciprianea. Per un'edizione critica dello pseudociprianeo De aleatoribus», Vetera Christianorum, 20, 1983, p. 169-170, $\mathrm{n}^{\circ} 21$.

5. Berlin, Staatsbibliothek zu Berlin - Preussischer Kulturbesitz, Hamilton 199, $\mathrm{XV}^{\mathrm{e}}$ s., f. $210 \mathrm{v}-213 \mathrm{r}$

Origine: Italie

Bibl. : H. BOESE, Die lateinischen Handschriften der Sammlung Hamilton zu Berlin, Wiesbaden, 1966, p. 102-103; M. MARIN, «Problemi di ecdotica ciprianea», p. 168-169, nº 19.

6. Bologna, Bibl. Univ. 2364, $X V^{\mathrm{e}}$ s. (sigle $B$ ), f. 170r-172r

Provenance: acquis en 1472 par le monastère San Salvatore. C'est le manuscrit utilisé par Trombelli pour l'édition princeps ${ }^{18}$.

Bibl.: L. FraTI, «Indici dei codici latini conservati nella R. Biblioteca Universitaria di Bologna», Studi italiani di filologia classica, 17, 1909, p. 33-34, n 1192; M. BÉVENOT, St. Cyprian's De unitate Chap. 4 in the Light of the Manuscripts, Romae, 1937, p. XXX-XXXI, XXXII, n. 47 ; M. MARIN, «Problemi di ecdotica ciprianea», p. 184-185, n 38.

7. El Escorial, Bibl. del Real Monasterio de San Lorenzo a. II. 12, XVI ${ }^{\mathrm{e}}$ s., f. $30 \mathrm{v}-33 \mathrm{v}$

Remarque: les œuvres de Cyprien sont suivies d'une série de traités théologiques sans nom d'auteur et du De legibus et senatusconsultis d'Antonio Agustín (cette partie est autographe).

Bibl.: G. AnTolín, Catálogo de los códices latinos de la Real Biblioteca del Escorial, I, Madrid, 1910, p. 57-60; M. MARIN, «Problemi di ecdotica ciprianea», p. 203, n ${ }^{\circ} 52$.

8. Notre Dame, University Library 44, milieu du XVe s., f. 217r-219r

Origine: sud de la France

Bibl.: J.A. CORBETT, Catalogue of the Medieval and Renaissance Manuscripts of the University of Notre Dame, Notre Dame, 1978, p. 193-202; description en ligne sur le site de Digital Scriptorium (http://scriptorium.columbia.edu/).

9. Paris, BnF, n. a. lat. $1282,1^{\mathrm{e}}$ moitié du XV $\mathrm{X}$ s., f. $211 \mathrm{v}-213 \mathrm{v}$

Origine: Italie

Bibl. : L. DELISLE, Bibliothèque Nationale. Manuscrits latins et français ajoutés aux fonds des nouvelles acquisitions pendant les années 1875-1891, I, Paris, 1891, p. 203-204; M. BÉVENOT, St. Cyprian's De unitate Chap. 4, p. XXXII-XXXIV; C. SAMARAN et R. MARICHAL, Catalogue des manuscrits latins en écriture latine portant des indications de date, de lieu ou de copiste,

1961, pour les traités, et à G. F. DIERCKS, Sancti Cypriani episcopi epistularium. Prolegomena: codices, editiones, indices, Turnhout, 1999 (CCSL 3D), pour les lettres.

18. Voir p. 104. 
IV, 1, Bibliothèque nationale. Fonds latin (Supplément), nouvelles acquisitions latines, petits fonds divers, Paris, 1981, p. 370; M. MARIN, «Problemi di ecdotica ciprianea», p. 197, $\mathrm{n}^{\circ} 45$.

10. Roma, Bibl. Vallicelliana A 18, XV s. f. 197r-199v

Bibl. : M. MARIN, «Problemi di ecdotica ciprianea», p. 191-194, n 43.

11. San Marino, Huntington Library, HM 1040, $X V^{\mathrm{e}}$ s. [1456], f. 230r-233r

Origine : copié à Rome par Bartholomeus de Schianchis (souscription au f. 240r)

Bibl.: A. DEROLEZ, Codicologie des manuscrits en écriture humanistique sur parchemin, I, Turnhout, 1984, p. 130, n6 67; C.W. DUTSCHKE avec la collab. de R. H. ROUSE et al., Guide to Medieval and Renaissance Manuscripts in the Huntington Library, I, San Marino, 1989, p. 308-311, ainsi que: http://sunsite3.berkeley.edu/hehweb/HM1040.html (24 octobre 2010).

12. Vaticano, BAV, Ottob. lat. $306, X V^{e}$ s., f. $264 v-267 v$

Provenance: cardinal Cervini (poss.)

Bibl. : F. FOSSIER, « Premières recherches sur les manuscrits latins du Cardinal Marcello Cervini (1501-1555)", Mélanges de l'École Française de Rome, Moyen-Âge - Temps Modernes, 91, 1979, p. 422, 447; M. MARIN, «Problemi di ecdotica ciprianea», p. 171-172, n 23.

13. Vaticano, BAV, Ross. $250, \mathrm{XV}^{\mathrm{e}}$ s. [1451], f. $267 \mathrm{~V}-270 \mathrm{v}$

Origine: copié à Florence par Hieronymus Pistoriensis pour le cardinal Francesco Condulmer (souscription au f. 288v).

Bibl. : H. TIETzE, Die illuminierten Handschriften der Rossiana in Wien-Lainz, Leipzig, 1911, p. 126, n² 270; M. MARIN, «Problemi di ecdotica ciprianea», p. 187-189, n 41; A. DEROLEZ, Codicologie des manuscrits en écriture humanistique sur parchemin, $\mathrm{I}, \mathrm{p} .139, \mathrm{n}^{\circ} 154$.

14. Vaticano, BAV, Vat. lat. 200, XV' s. [1456], f. 247r-250r

Origine : copié pour Filippo Calandrini par Georgius Kynninmonth Scotus (souscription au f. 258r), qui était actif à Rome.

Bibl. : M. VATTASSO et P. FRANCHI DE'CAVALIERI, Codices Vaticani Latini, I, Codices 1.687, Romae, 1902, p. 156-158; M. MARIN, «Problemi di ecdotica ciprianea», p. 174-175, nº 27; A. DEROLEZ, Codicologie des manuscrits en écriture humanistique sur parchemin, I, p. 139, $n^{\circ} 136$.

15. Vaticano, BAV, Vat. lat. 5099 , XV $\mathrm{XV}^{\mathrm{e}}$ s., f. $186 \mathrm{r}-188 \mathrm{v}$

Origine: copié en Italie 19

Bibl. : M. BÉvenot, St. Cyprian's De unitate Chap. 4, p. XXXI-XXXII; M. MARIN, «Problemi di ecdotica ciprianea $»$, p. $175-176, \mathrm{n}^{\circ} 28$.

19. M. BÉvenot, St. Cyprian's De unitate Chap. 4, p. XXXII, n. 49, déduit du colophon au f. 207 v, Scribi fecit praesul vigintimilliensis, que l'évêque de Vintimille, Carlo Visconti, qui défend le texte de l'édition romaine pour les passages discutés du De unitate, possédait le volume qu'il avait hérité de son prédécesseur. 
On ajoutera un manuscrit aujourd'hui disparu:

16. Venezia, San Michele di Murano fol. $28, \mathrm{XV}^{\mathrm{e}} \mathrm{s}$.

Bibl.: G.B. MITTARELL1, Bibliotheca codicum manuscriptorum monasterii S. Michaelis Venetiarum prope Murianurn una cum appendice librorum impressorum seculi $\mathrm{XV}$, Venetiis, 1779 , c. 302-305; H. VON SODEN, Die cyprianische Briefsammlung, p. 140; M. MARIN, «Problemi di ecdotica ciprianea», p. 194, 203, n. 48.

On peut schématiser le contenu des recentiores de la manière suivante 20 :

1. Traités suivis de lettres

2. Une partie des manuscrits a la lettre 32 , déjà présente dans la collection de lettres. Les autres manuscrits ont éliminé ce doublon.

3. L'Ad Vigilium episcopum de Iudaica incredulitate, indûment attribué par les manuscrits à Cyprien de Carthage $\left(C P L 67^{\circ}\right)$

4. La lettre 75 du corpus épistolaire (adressée par Firmilien de Césarée à Cyprien)

5. Une partie des manuscrits a ici la Vita Cypriani (jusqu'au $\$ 15,4$ ) suivie des Acta proconsularia (BHL 2039b).

6. Paen

7. Certains manuscrits ajoutent le De duodecim abusiuis saeculi, attribué ici à Cyprien, et un autre appendice comportant des textes pseudépigraphes et des lettres (essentiellement des lettres de correspondants).

Ce groupe de manuscrits témoigne de la grande diffusion du texte de Cyprien en Italie au $\mathrm{XV}^{\mathrm{e}} \mathrm{s}$. et de la productivité d'une collection cyprianique qui offrait l'avantage d'être assez complète. Il témoigne également de la volonté de rassembler toute l'œuvre circulant sous le nom de Cyprien, ainsi que les textes associés à son œuvre, ce qui a entraîné l'adjonction, en appendice, de textes aujourd'hui reconnus comme inauthentiques ou de lettres de correspondants, écrits qui ne figuraient pas dans les séries principales de lettres.

Paen figure enfin dans $M$, copié en 1416 sur un manuscrit qui appartenait à Pedro de Luna:

17. Madrid, Bibl. Nac. 5569 (olim Q 138), XVe [1416] (sigle $M$ ), f. $149 \mathrm{rb}-151 \mathrm{va}$

Origine: copié pour dom Alfonso Carrillo sur un manuscrit appartenant à l'antipape Benô̂t XIII'21.

Bibl. : Inventario general de manuscritos de la Biblioteca nacional, X (3027 a 5699), Madrid, 1984 , p. 413.

20. Seul l'appendice qui comporte Paen présente de l'intérêt pour notre étude. Pour le détail de la collection de traités et de lettres, qui peut prendre deux formes différentes selon les manuscrits ici mentionnés, on se reportera à G. F. DiERCKs, Prolegomena, p. 812-815, qui répertorie ces manuscrits dans le groupe 22. G.F. Diercks actualise le travail de H. VON SODEN, Dic cyprianische Briefsammlung, p. 138-141, qui, sur la base de l'ordre des lettres, avait déjà pressenti la parenté de ceux des manuscrits qui lui étaient connus.

21. Souscription au f. 187: Die sabbato XVIII mensis Iullii anno Domini MCCCCXVI ego aluarus ypsalensis familiarius reuerendissimi in christo patris domini Alfonsi Carillo sancti Eustachii S. R. E. diachoni Card. perfeci hunc librum de eiusdem domini mandato. Copiaui de quodam libro sanctissimi domini nostri papae Benedicti XIII. 
Ce manuscrit est également composé d'œuvres de Cyprien, mais il présente une collection différente de celle des manuscrits précédents. Le manuscrit s'achève avec les textes suivants 22 :

1. Trois lettres de Cyprien : $32,10,80$

2. L'Ad Vigilium episcopum de Iudaica incredulitate

3. La lettre 75

4. Plusieurs lettres de Cyprien: $15,17,18,19,26,25,9,29,7$

5. La Vita Cypriani

6. Paen

7. Le De duodecim abusiuis saeculi, ici attribué à Cyprien

\section{B. Les rapports entre les manuscrits}

Cette répartition des manuscrits en deux ensembles, fondée sur des données externes (la date et le contenu), se voit confirmée par l'analyse des variantes textuelles. Les recentiores ont en commun un nombre élevé de fautes propres ${ }^{23}$ :

11. suis om. recentiores

13. ut: aut recentiores

17. salueris: saneris recentiores

19. sudans: suadens recentiores

24. quia: et recentiores

31. existimati sunt om. recentiores

34. respondete ea: respondete ei recentiores

Les manuscrits italiens et le manuscrit de Notre Dame (mss it.) constituent un sous-ensemble caractérisé par des fautes qui leur sont propres; dans ces cas-là, $M$ a conservé le bon texte, comme les manuscrits plus anciens:

3. sponsionem: s. meam mss it.

8. nubem om. mss it.

8. nimbum: imbrem mss it.

29. quaecumque: quae mss it.

32. reuerens: ueritas mss it.

37. sancti om. mss it.

38. correptum: correctum mss it.

Les recentiores, où Paen est agrégé au corpus des œuvres de Cyprien, transmettent donc un texte dégradé. On peut proposer le stemma suivant pour cette partie de la tradition:

22. Pour une description complète du contenu, on se reportera à G.F. DIERCKs, Prolegomena, p. 769 .

23. À l'exception de celui de Notre Dame, tous les manuscrits ont été collationnés. Je remercie Mickaël Ribreau qui a collationné pour moi le manuscrit de la Vallicelliana. 


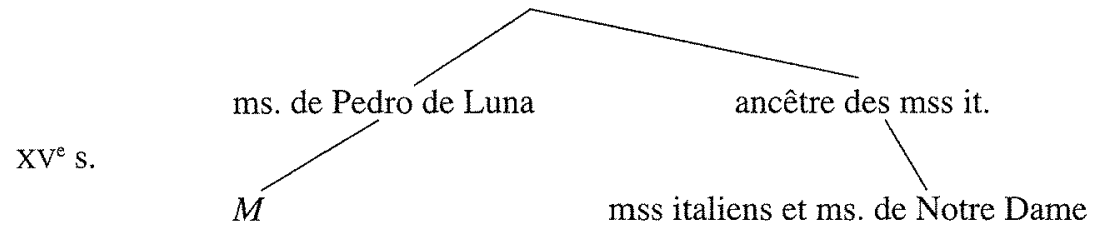

En raison de la nature du texte et de sa brièveté, il n'est pas possible de dresser avec plus de précision la généalogie des recentiores. L'examen des variantes permet toutefois de supposer un lien plus étroit entre les manuscrits $A, B$, Vat. lat. 5099, les manuscrits de Rome, Paris et de l'Escorial:

18. auersione: a uisione

31. generatione et generationem: generatione

32. tribulat: tribuat

40. beati pauli : pauli beati

$G, H$ et $P$, les manuscrits les plus anciens, ne constituent pas une famille: ils ne partagent pas de fautes qui leur soient propres là où les recentiores auraient gardé le bon texte. En pratique, ces trois manuscrits sont suffisants pour établir Paen et les recentiores peuvent être négligés. Est-il possible de préciser les relations entre les trois témoins? On pourrait s'attendre à ce que $H$ (Chaalis) soit copié sur $G$ (Pontigny). Si la relation est plausible en raison de la filiation entre les deux abbayes, aucun lieu variant de $P a e n$ n'apporte de confirmation décisive ${ }^{24}$. $P$ est une copie assez négligée, comme en témoignent les petites omissions ou fautes de copie qui sont rectifiées par le scribe. $P$ comporte aussi un certain nombre de leçons fautives:

34. flos: $\operatorname{ros} P$

37. demoreris: dormieris $P$

44. fundamentum: firmamentum $P$

$P$ a-t-il pu conserver seul le bon texte? Les leçons qu'il a en propre sont en général fautives, et nous avons toujours retenu le texte de $G$ et $H$ contre celui de $P^{25}$.

24. À propos des liens entre les manuscrits de Pontigny et de Chaalis, cette remarque de M. PEYRAFORT-HuIn, La bibliothèque médiévale de l'abbaye de Pontigny, p. 103, incite à la prudence: «Dans le cas de Chaalis, on peut s'attendre à ce que l'abbaye-mère, Pontigny, ait fourni des modèles à sa fille directe, Chaalis; cependant la période de constitution des deux bibliothèques étant peut-être plus rapprochée que ne pourraient le laisser croire leurs dates de fondation respectives, il convient de rester prudent et de ne déterminer le sens des échanges qu'après une datation approximative des exemplaires. »

25. En étudiant le texte biblique, on examinera toutefois un petit nombre de cas où le texte de $P$ comporte une leçon intéressante: 34 . deprecamini ; 35 . et ego; 45 . excideris. 
L'ancêtre des manuscrits conservés comportait quelques fautes:

4. faucem: faciem codd.

11. bilem: uilem codd.

13. quae: quod codd.

32. iudicantur: iudicant codd.

À côté de ces cas indiscutables, il y a des passages où il est plus difficile de savoir si une intervention de l'éditeur est légitime: le texte transmis offre un sens, mais s'écarte des autres versions latines du même texte biblique et de ce que laisserait attendre le grec. Cet écart peut résulter d'une faute aisément explicable d'un point de vue paléographique, mais on ne peut exclure non plus qu'il corresponde à une variante reçue du texte biblique latin qu'il faudrait alors laisser telle quelle. En voici deux exemples:

9. priora saecula codd. (Is 46,9 ), alors que, d'après le grec, on attendrait : priora a saeculo. Faut-il corriger en supposant une modification consécutive à un phénomène d'haplographie au cours de la transmission 26 ? Faut-il éditer le texte en suivant les manuscrits et le considérer comme une variante du texte biblique ? R. Gryson, éditeur d'Isaïe dans la Vetus Latina, fait figurer «priora saecula» comme une variante du texte biblique.

20. mala codd. (Jr 18, 12), alors qu'on attendrait, conformément au grec, malo, en accord avec cordi suo. Mais mala peut être considéré comme le complément de faciemus et l'antécédent de quae. Là encore, on peut se demander s'il s'agit d'une simple confusion entre $o$ et $a$, ou s'il faut y voir une variante qui remonte à la version latine utilisée.

Nous avons pris le parti de ne corriger que lorsque c'était indispensable pour le sens.

Il ressort de l'étude des variantes que les recentiores ne sont d'aucune utilité pour établir le texte. Peut-on apporter quelques précisions sur la manière dont ils se rattachent aux trois manuscrits les plus anciens? L'histoire des collections cyprianiques et l'histoire du texte de Cyprien permettent d'établir un lien entre les recentiores et le milieu cistercien.

On a rappelé le principe qui préside à l'enrichissement des collections cyprianiques. Il s'agit visiblement de rassembler tout ce qui circule sous le nom de Cyprien. L'ancêtre commun des manuscrits italiens et du manuscrit de Notre Dame disposait donc d'une source où Paen figurait sous le nom de l'évêque de Carthage et qui a servi à compléter un corpus déjà important de ses œuvres. Le contexte de Paen dans ces manuscrits ne donne qu'un accès partiel à cette source: amputée de tous les textes qui figuraient dans le manuscrit, déjà très riche, elle n'est plus immédiatement reconnaissable. Ajoutons que cette source devait être elle-même peu diffusée, car le seul autre manuscrit où l'on trouve Paen comme enrichissement d'une collection cyprianique est le manuscrit de Madrid. Une

26. L'hypothèse est mentionnée par R. GRYSON, Vetus Latina. Die Reste der altlateinischen Bibel, 12. Esaias, p. 1116. 
comparaison entre l'ordre des textes dans $M$ et les manuscrits italiens permet de constater plusieurs similitudes: la succession de l'Ad Vigilium et de la lettre 75 est la plus frappante. De manière générale, la fin des manuscrits italiens s'explique parfaitement si un manuscrit présentant l'ordre de $M$ a servi à compléter leur modèle commun: ont été omis - imparfaitement en ce qui concerne la lettre 32 , copiée dans certains manuscrits, éliminée dans d'autres - les textes déjà présents dans la partie principale du manuscrit ${ }^{27}$.

$M$ descend d'un manuscrit qui appartenait à Pedro de Luna. La copie ayant été réalisée en 1416, le modèle figure certainement dans le catalogue de Peñiscola, mais il ne s'identifie à aucun des «Cyprien» décrits de manière détaillée ; il correspond sans doute à l'un des deux manuscrits dont le contenu n'est pas précisée ${ }^{28}$. Si l'on s'en tient à l'ordre des textes, la collection du manuscrit de Madrid - et de son modèle - peut s'analyser comme une double sélection opérée dans un corpus comparable à celui qui était attesté à Cîteaux, avec le manuscrit Dijon, Bibl. mun. 124, $\mathrm{XII}^{\mathrm{e}} \mathrm{s}^{29}$, et augmentée de Paen et du De duodecim abusiuis saeculi. Le manuscrit de Dijon transmet une collection d'écrits de Cyprien qui circule plus largement, en milieu cistercien et en Champagne ${ }^{30}$. Par rapport aux autres manuscrits cisterciens de Cyprien, le manuscrit de Cîteaux se caractérise par un supplément de lettres aisément reconnaissable dans le manuscrit de Madrid: 75, 15, 17, 18, 19, 26, 25 ,

27. C'est-à-dire les lettres 10 et 80 d'une part, les lettres $15,17,18,19,26,25,9,29$ et 7 d'autre part.

28. Le catalogue de la bibliothèque du château de Peñiscola (1412-1415) recense sept manuscrits comportant des écrits de Cyprien. Quatre d'entre eux sont décrits de manière détaillée, mais ne correspondent pas au modèle de $M$ (les nos $225,434,510$ et 556 de l'édition de M. Faucon, La librairie des papes d'Avignon. Sa formation, sa composition, ses catalogues [1316-1420], II, Paris, 1887). Il faut également exclure le $n^{\circ} 435$. Le contenu cyprianique n'est pas précisé, mais le catalogue énumère en détail les autres textes que contenait le manuscrit, ce qui permet de l'identifier dans l'inventaire après décès de 1423 : il correspond au $\mathrm{n}^{\circ} 489$ de l'inventaire $\mathrm{Pb}$, publié par J. MONFRIN et M.-H. JULLIEN DE POMMEROL, La bibliothèque pontificale à Avignon et à Peñiscola pendant le Grand schisme d'Occident et sa dispersion: inventaire et concordances, Paris-Rome, 1991; la notice précise qu'il y avait seulement huit lettres de Cyprien. Le modèle de $M$ se dissimule donc vraisemblablement sous les $n^{\text {os }} 433$ ou 436 (Item epistole Cipriani) du catalogue de Peñiscola. Le contenu des nos 433 et 436 n'est pas décrit de manière plus précise dans l'inventaire après décès (sous les $\mathrm{n}^{\text {os }} 502$ et 779 ). Toutefois la description matérielle des deux volumes permet de voir qu'ils figuraient déjà vraisemblablement dans l'inventaire que fit dresser Urbain V en 1369 (sous les n 741 et 481 dans l'édition de M. FAUCON, op. cit., I, p. 70, 136 et 158). Après la mort de Pedro de Luna, l'un des volumes revint au notaire, Antoine de Camps, l'autre fut envoyé à Valence pour y être vendu.

29. Une première sélection de traités et de lettres, suivie d'un second choix de traités et de lettres. La démonstration, fondée sur l'ordre des textes, est faite par H. VON SODEN, Die cyprianische Briefsammlung, p. 150-151.

30. La liste des témoins est dressée par M. BÉVENOT, St. Cyprian's De unitate Chap. 4, p. XLV; G.F. DIERCKs, Prolegomena, p. 764-765. 
$9,29,7,(56)^{31}$. L'hypothèse d'un lien entre la collection cistercienne de Cyprien et $M$, fondée sur l'ordre des textes, trouve une confirmation dans l'analyse des variantes. Dans son édition des lettres de Cyprien, G.F. Diercks classe en effet $M$ avec les manuscrits cisterciens ${ }^{32}$. On aboutit à des conclusions plus précises en considérant le cas de l'Ad Vigilium ${ }^{33}$, transmis dans le voisinage immédiat de Paen. Pour ce texte, les manuscrits cisterciens sont les plus anciens témoins d'une classe de manuscrits définie par un petit nombre de fautes communes et qui se subdivise en trois groupes nettement caractérisés. Le manuscrit de Dijon est le témoin principal du deuxième de ces groupes, qui transmet un texte profondément altéré pour l'Ad Vigilium. Le manuscrit $M$ et les manuscrits italiens sont des représentants plus tardifs de ce texte corrigé. Ainsi, sur la base de critères externes et internes, on arrive à la conclusion que l'exemplaire de Pedro de Luna a exploité un manuscrit présentant le même corpus que celui dont témoigne aujourd'hui le manuscrit de Cîteaux. Or la plus ancienne attestation de Paen est également d'origine cistercienne (manuscrits $G$ et $H$ ). On peut donc dire que le modèle de $M$ réalisait la fusion de deux sources attestées pour la première fois en milieu cistercien: la collection cistercienne augmentée, telle qu'on la trouve à Cîteaux ${ }^{34}$, et Paen. Il y a naturellement des intermédiaires qui nous échappent, mais on peut dire que les recentiores, pour la totalité du corpus dans le cas de $M$ et de son modèle, pour l'appendice contenant l'Ad Vigilium et Paen dans les autres manuscrits, sont un lointain produit de cet état du travail sur le texte de Cyprien

31. La lettre 56, qui figure de manière incomplète et pour la seconde fois dans le manuscrit de Cîteaux, n'est pas conservée dans la section correspondante du manuscrit de Madrid.

32 G. F. DIERCKs, Prolegomena, p. 769. Il semble en réalité qu'il n'ait collationné le manuscrit que pour les lettres de Novatien (Prolegomena, p. 769, n. 41). Voir le stemma qu'il dresse dans Nouatiani opera quae supersunt nunc primum in unum collecta ad fidem codicum qui adhuc extant necnon adhibitis editionibus ueteribus, Turnhout, 1972 (CCSL 4), p. 194 pour la lettre 30 , et p. 223 pour la lettre 31 . Il n'a pas utilisé le manuscrit pour la lettre 75 , pourtant faiblement diffusée, ce qui l'a obligé à élargir sa base manuscrite habituelle, cf. Sancti Cypriani epistularium, Turnhout, 1996 (CCSL 3C), p. 581 et Prolegomena, p. 833.

33. Nous résumons les résultats auxquels nous sommes parvenue dans notre thèse de doctorat, L'héritage littéraire de Cyprien de Carthage à travers les écrits pseudépigraphes, sous la direction de V. Zarini, Université Paris IV-Sorbonne, décembre 2007, p. 246-248.

34. Le manuscrit de Dijon a deux descendants, Paris, BnF, lat $1650,3^{c}$ quart du $\mathrm{XI}^{\mathrm{e}} \mathrm{s}$. (Fontenay), et Troyes, Bibl. mun. 37, xire s. (Clairvaux). Dans ces deux manuscrits, l'ordre des lettres est modifié par rapport au modèle de Cîteaux, pour tenir compte des annotations portées dans la marge du manuscrit (la démonstration est faite par M. BÉVENOT, St. Cyprian's De unitate Chap. 4, p. XLVII-LII ; voir aussi G.F. DIERCKS, Prolegomena, p. 766, et D. STUTZMANN, La bibliothèque de l'abbaye cistercienne de Fontenay [Côte-d'Or]. Constitution, gestion, dissolution [XII-XVIII siècle], Thèse de l'École des Chartes, 2002, I, p. 153-157): ainsi, les lettres ajoutées par le manuscrit de Citeaux se trouvent dans les descendants de Fontenay et de Clairvaux à la place que leur a attribuée l'annotateur. Le manuscrit $M$ suppose une source qui correspond, pour l'ordre des textes, à l'état de la collection cistercienne attesté par le manuscrit de Cîteaux. 
en milieu cistercien ${ }^{35}$. L'abbaye de Pontigny offre l'exemple d'une bibliothèque où se trouvaient à la fois un manuscrit des traités et des lettres de Cyprien ${ }^{36}$ et un manuscrit de la collection patristique contenant Paen.

En s'appuyant sur la circulation de collections cyprianiques bien attestées, on comprend donc assez bien comment le texte, transmis sous le nom de Cyprien, a pu être récupéré par des manuscrits qui avaient pour vocation de rassembler tout ce qui circulait sous le nom de l'évêque de Carthage. Ce glissement vers le corpus des cuuvres de Cyprien a favorisé la diffusion de Paen, qui serait restée médiocre sans cela.

En dépit d'un nombre significatif de manuscrits, la reconstitution de l'histoire du texte débouche sur une impasse. Paen semble être mis en circulation au XII ${ }^{\mathrm{e}} \mathrm{s}$, en milieu cistercien. On ne peut préciser où les cisterciens ont récupéré ce bloc de citations bibliques. L'étude des collections de $G H$ et de $P$ ne fournit pas d'indice: la collection de $G H$, visiblement réunie pour répondre à des besoins monastiques, comporte des textes courants; dans $P$, Paen est copié à la suite d'une série d'écrits spirituels eux aussi fort répandus.

La tradition imprimée, exclusivement dépendante des manuscrits connus et en particulier des recentiores, n'apporte pas d'éléments nouveaux sur ce point.

\section{La tradition imprimée}

Il fallut attendre le milieu du XVIII' s. pour que Paen fasse l'objet d'une édition. Le texte figure pourtant dans plusieurs manuscrits italiens qui furent possédés ou consultés par des prélats ou des savants qui s'intéressaient à l'édition de Cyprien ${ }^{37}$.

35. Le modèle de $M$ n'était pas le seul manuscrit de la bibliothèque des Papes d'Avignon à avoir comme source lointaine une collection cistercienne. Le manuscrit de Carpentras, Bibl. Inguimbertine 31, XIV $V^{e}$ s., comporte une ample collection d'œuvres de Cyprien, que le catalogue de Peñiscola décrit dans deux manuscrits différents ( ${ }^{\circ s} 225$ et 510 de l'édition de M. FAUcon, op. cit; ; les deux manuscrits diffèrent pour leur contenu non-cyprianique; le manuscrit de Carpentras est en tout point identique au n ${ }^{\circ} 510$ ). Sa seconde partie (à partir de l'Ad Fortunatum) est depuis longtemps analysée comme une sélection faite à partir d'un manuscrit cistercien (cf. H. VON SODEN, Die cyprianische Briefsammlung, p. 149) et G.F. DIERCKs le classe pour le texte des lettres avec les manuscrits cisterciens (Prolegomena, p. 769-770).

36. Il n'en subsiste qu'un seul fragment, New York, Columbia University Library, Plimpton ms $51,3^{\mathrm{c}}$ quart du XII $\mathrm{s}$., décrit dans M. PEYRAFORT-HunN, La bibliothèque médiévale de l'abbaye de Pontigny, p. 549. Il correspond au volume A 73 de l'inventaire médiéval (p. 258-259).

37. Le manuscrit Ottob. lat. 306 par exemple appartenait au cardinal Cervini, cf. P. PETITMENGIN, «Le Codex Veronensis de Saint Cyprien. Philologie et histoire de la philologie», Revue des études latines, 46, 1969, p. 332-333. Paen se trouve également dans l'un des manuscrits qui ont servi aux. travaux préparatoires à l'édition romaine de 1563, le Vat. lat. 200, cf. P. PETITMENGIN, «Le Codex Veronensis de Saint Cyprien», p. 348, n. 2. Le manuscrit de Bologne a été vu par Latino Latini lors de son séjour en 1565 dans cette ville, voir sur ce point LaTINo LATINI, Bibliotheca sacra siue obseruationes, coniecturae et uariae lectiones in sacros et profanos scriptores e marginalibus notis codicum eiusdem a Dominico Marco ... collectae, Romae, 1677, p. 174 et M. BÉVENoT, 
Faut-il penser que ce court texte a échappé à l'attention ? Ou qu'il n'a pas été jugé suffisamment digne d'intérêt en raison de son contenu, uniquement biblique, et de sa brièveté ? Giovanni Grisostomo Trombelli, chanoine régulier de San Salvatore, le découvre dans l'un des deux «Cyprien» du monastère. La trouvaille est mentionnée en 1747 dans une lettre à Muratori (24 juillet); quelques jours plus tard, il lui envoie une transcription de Paen et annonce qu'il dotera le texte d'une annotation et d'un commentaire (lettre du 7 août) ${ }^{38}$. Trombelli publie Paen en 1751 sur la base d'un seul témoin. Wunderer et, à sa suite, Miodoński et von Soden pensaient ce manuscrit perdu, mais il faut sans hésitation identifier la source de l'édition avec le manuscrit conservé à la bibliothèque universitaire de Bologne, sous la cote 2364 (sigle $B$ ). Une note sur le dernier feuillet précise qu'il fut acheté en 1472 par le monastère San Salvatore. Les feuillets de garde comportent des notes d'une main du XVIII ${ }^{e} \mathrm{~s}$. dans laquelle il faut sans doute reconnaître celle de Trombelli. Le contenu du manuscrit y est décrit avec précision et comparé avec l'édition Baluze: sont d'abord énumérés les lettres, puis les traités. L'auteur des notes souligne que le manuscrit contient presque toute l'œuvre authentique de Cyprien et une bonne partie des textes qui lui sont attribués; il offre en outre un texte inédit, Paen, qui lui paraît ancien et qui semble adressé à des Novatiens. Il est tentant de voir dans ces notes une trace du travail d'identification que mentionne Trombelli dans sa préface et qui conduisit à l'édition du petit texte ${ }^{39}$.

L'édition Trombelli comporte des fautes caractéristiques de la seconde famille. Cependant Trombelli ne reproduit pas servilement sa source. Lorsqu'une faute lui semble évidente, il n'hésite pas à corriger le texte ${ }^{40}$. Il faut aussi supposer dans certains cas des erreurs de lecture ${ }^{41}$. On note également deux écarts entre le texte imprimé, que nous suivons pour notre apparat critique, et les lemmes du commentaire qui suit l'édition ${ }^{42}$, qui ont conservé, semble-t-il, le texte de $B$ :

$\mathrm{n}^{\circ} 27$ : l'édition a uiuet, tandis que le commentaire a uiuat (comme $B$ )

$\mathrm{n}^{\circ} 44$ : l'édition a discedet, tandis qu'on lit discedat dans le commentaire (comme $B$ )

St. Cyprian's De unitate Chap. 4, p. XXX-XXXI.

38. Ces deux lettres, $n^{\text {os }} 45$ et 46 , sont éditées par G. MALAGUTI, «Lettere di Giovanni Grisostomo Trombelli a Ludovico Antonio Muratori», dans Giovanni Grisostomo Trombelli (1697-1784) e i canonici regolari del SS. Salvatore, M. G. Tavoni et G. Zarri (éd.), Modena, 1991, p. 169 et 204-205.

39. Quae dum solertissime perquiro comparoque cum editis, se mihi libellus obtulit, quem inter euulgatos frustra perquisiui, PL 4, c. 1151. Les notes se trouvent sur les feuillets numérotés 1 à 4 du manuscrit; ils ne sont pas reliés dans l'ordre, le f. 3 qui décrit les vingt-deux premières lettres vient en tête.

40. Voir par exemple $\mathrm{n}^{\text {os }} 6$ (deleo), 13 (ne audiant), 21 (currens fluuius), 44 (sicut).

41. Par exemple l'omission d'iniquitates dans l'extrait $\mathrm{n}^{\circ} 30$.

42. Commentaire reproduit dans la Patrologie Latine, t. 4, c. 1157-1190. 
Le texte, suivi de son commentaire, est réimprimé dans la Patrologie Latine, t. 4 , c. $1153-1158$, avec quelques erreurs supplémentaires ${ }^{43}$. Alors qu'il pouvait connaître Paen par la Patrologie Latine, Hartel, l'éditeur de Cyprien et des œuvres attribuées à Cyprien dans le corpus de Vienne (1868-1871), ne le reproduit pas, sans s'en expliquer. Hartel choisit d'exclure les pseudépigraphes qui ont retrouvé leur auteur, les textes jugés trop folkloriques ou trop récents ${ }^{44}$, critères qui s'appliquent mal à Paen. Peut-être Paen a-t-il été laissé de côté faute de témoins manuscrits: en effet le texte n'est pas transmis par les manuscrits qu'utilise Hartel pour éditer les autres œuvres du corpus.

Paen sera encore édité deux fois à la fin du XIX $\mathrm{s}$. Dans son édition, qui paraît en $1889^{45}$, C. Wunderer utilise A (Augsburg, Staats- und Stadtsbibliothek, Fol. Cod. 65), qu'il a collationné lui-même, et $M$ dont il a obtenu une collation. Avec le manuscrit $M$, moins fautif que ses cousins italiens, Wunderer disposait d'un témoin intéressant qui lui a permis de corriger le texte de Trombelli à plusieurs reprises. Il accorde toutefois généralement la préférence à $A$, qu'il juge plus fiable, et rejette des leçons pourtant correctes de $M$ en apparat ${ }^{46}$. On doit également à Wunderer quelques conjectures qui seront confirmées par les manuscrits plus anciens (par exemple ut auferam; in summa au $n^{\circ} 13$; sudans au $\mathrm{n}^{\circ} 19$ ).

L'apport d'A. Miodoński (1894) est plus substantiel ${ }^{47}$. Avec le manuscrit de l'Arsenal $(P)$, il dispose d'un témoin plus ancien, qui évite toutes les fautes de la famille dont $M$ et $A$ sont les représentants. Il comble par exemple les deux petites lacunes de l'édition princeps aux $\mathrm{n}^{\text {os }} 6$ et 31 . Cependant, il hésite à suivre $P$ lorsque celui-ci offre un texte qui ne lui paraît pas attesté ailleurs en latin ${ }^{48}$.

L'examen de l'histoire de la tradition manuscrite modifie quelque peu notre vision du texte: Paen apparait comme un bloc de citations bibliques qui surgit dans la seconde moitié du XII' $\mathrm{s}$, et dont on n'a pas de trace auparavant. La forme du texte et sa transmission incitent à la prudence pour proposer une datation. Que nous apportent les éléments internes au texte pour le dater et le localiser?

43. Ajouter et après estis en Paen 9; lire nemorosum au lieu de numerosum en Paen 23, miserebitur au lieu de miserabitur en Paen 24 ef domino au lieu de domini en Paen 33.

44. W. HARTEL, Thascii Caecilii Cypriani opera omnia, 3, Vindobonae, 1871, p. LXXXVII; L.IX.

45. C. WUNDERER, Bruchstücke einer afrikanischen Bibelübersetzung in der pseudocyprianischen Schrift Exhortatio de paenitentia neue bearbeitet, Erlangen, 1889.

46. C. WUNDERER, éd. cit., p. 10. Voir par exemple $\mathrm{n}^{\text {os }} 8$ (nimbum), 13 (et regnum), 21 (currens flunius).

47. A. MIODONSKK, «Incerti auctoris Exhortatio de paenitentia», Rozprawy Akademii Umiejętności. Wydziat Filologiczny, 2, 5, 1894, p. 125-134.

48. Voir par exemple les $\mathrm{n}^{\text {os }} 21$ (currens fluuius), 25 (fecit, auerterit). 


\section{III. - DATATION ET LOCALISATION}

Nous ne nous attarderons pas sur les raisons qui obligent à rejeter l'attribution à Cyprien, qui ne fut d'ailleurs défendue que par le premier éditeur du texte. L'éventail des citations bibliques ne recoupe pas celui qu' on trouve dans l'œuvre de Cyprien ${ }^{49}$ : outre des absences remarquables sur le thème de la pénitence ( $\mathrm{Jl} 2$, 12-13 par exemple ${ }^{50}$ ), on note la présence de textes qui ne sont jamais cités par Cyprien, comme les Lamentations. Au total vingt-deux versets seulement sont communs à Paen et à l'évêque de Carthage et permettent donc une comparaison entre les deux auteurs. On constate des divergences trop grandes dans la manière de citer les textes bibliques pour qu'elles puissent être le fait d'un même auteur, même si Cyprien ne cite pas la Bible de manière rigide et sait à l'occasion adapter son texte à son propos. On ajoutera que les découpages des citations ne sont pas toujours identiques; à deux reprises par exemple (Ps 88, 31-34; Ap 2, 5), Paen omet une partie d'un verset ${ }^{51}$. La technique du florilège enfin est tout à fait différente, même si l'on tient compte des incertitudes sur la forme originale du texte: les florilèges bibliques de Cyprien sont constitués de plusieurs dossiers, généralement plus courts que celui de Paen; l'ordonnance des citations ne suit pas exclusivement la succession des livres bibliques, et la part personnelle de Cyprien est plus grande, qu'il s'agisse des préfaces qui introduisent les différents recueils, des introductions aux citations qui sont plus variées, ou des commentaires plus ou moins développés par lesquels Cyprien précise l'orientation des citations sélectionnées et les lie les unes aux autres.

La nature du texte, exclusivement constitué de citations bibliques et dépourvu de partie originale, explique les difficultés de datation et de localisation. La seule partie originale est le titre-sommaire qui introduit les citations, mais ni le vocabulaire ni l'idée exprimée dans cette proposition ne sont de nature à orienter l'analyse sur les coordonnées de Paen. La datation et la localisation entérinées par les répertoires - Afrique, fin du $I V^{\mathrm{e}} \mathrm{s}$. ou début du $\mathrm{V}^{\mathrm{e}} \mathrm{s}$. - reprennent en fait les conclusions de Wunderer qui s'appuyait essentiellement sur une étude du

49. C. WUNDERER, éd. cit., p. 31-32.

50. Cf. CYPRIEN, Ep. 55, 22, 2; De lapsis, 29 et 36; De bono patientiae, 4.

51. Paen 1 : Si dereliquerint filii eius legem meam et in iudiciis meis non ambulauerint et mandata mea non custodierint, uisitabo in uirga iniquitates eorum et in uerberibus peccata eorum. Misericordiam autem mean non dispergam ab eis; l'auteur de Paen omet le v. 32b, toujours présent chez Cyprien lorsqu'il cite les v. 31 à 33, cf. Ad Quirinum, I, 1 (v. 28-34), De lapsis, 6 (v. 31-33) ou Ep. 11, 2, 1 (v. 31-33) dont nous citons ici le texte: Si dereliquerint fili legem meam et in iudiciis meis non ambulauerint, si iustificationes meas profanauerint et praecepta mea non obseruauerint, uisitabo in uirga facinora eorum et in flagellis delicta eorum. Cet exemple permet aussi de mesurer les différences entre les textes des deux auteurs. Autre exemple: Ap 2, 5 est cité dans Paen 45 de manière plus étendue que chez Cyprien (cf. CyPrIEN, Ep. 19, 1; Ep. 34, 1 ; De lapsis, 16: memento unde cecideris et age paenitentiam), mais omet et fac priora opera, $\mathrm{cf}$. Ep. 55, 22, 1: memento unde cecideris et age paenitentiam et fac priora opera. 
texte biblique. Le texte biblique, sur lequel nous nous arrêtons à présent, donne en réalité des indications sur la source de Paen et permet seulement de déterminer un terminus post quem.

\section{A. Le texte biblique}

Peut-on préciser la nature du texte biblique utilisé dans Paen? Les éléments d'analyse ici réunis s'appuient sur les travaux actuellement en cours sur la Bible latine. La portée des conclusions n'est pas la même selon que l'on dispose des volumes édités par le Vetus Latina Institut de Beuron ou non. En outre, certains livres sont représentés par plusieurs versets (Isaïe, Ézéchiel, Jérémie), ce qui permet de formuler des hypothèses plus solides, tandis que d'autres ne le sont que par quelques mots (Zacharie, l'Apocalypse).

\section{1) Un texte «vieux latin»}

Les citations de Paen sont empruntées à des formes «non vulgate» du texte biblique. Les extraits des prophètes, qui constituent l'ensemble le plus important, se distinguent fortement de la version de Jérôme sur l'hébreu. Ainsi, lorqu'Is 30, 15 est cité sous une forme identique à celle de Paen lors du huitième concile de Tolède en 653 , le texte est présenté comme une uetus translatio ${ }^{52}$. De nombreuses citations témoignent des ajouts caractéristiques de la LXX. Dans le cas d'Os 14,3 par exemple, le discours direct potens es dimittere peccata nostra est absent de la traduction de Jérôme d'après l'hébreu mais figure dans de nombreux témoins de la Septante ${ }^{53}$; Deum uestrum qui complète Dominum fait également partie des ajouts

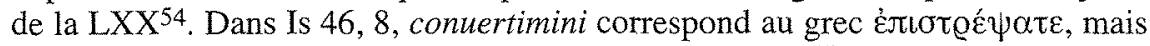
n'a pas de correspondant dans le texte traduit de l'hébreu ${ }^{55}$.

De manière générale, la comparaison entre Paen et la version de Jérôme montre que le texte latin repose sur le texte grec des LXX. Nous en donnons quelques exemples, empruntés à des livres différents:

- Is 30, 15 traduit fidèlement le texte grec; les différences de sens entre la version selon l'hébreu et selon les LXX sont précisément commentées par Jérôme dans son commentaire sur Isaï, IX, 22.

52. Éd. Vives, Concilios visigóticos e hispano-romanos, Barcelona-Madrid, 1963, p. 269 : etenim iuxta ueterem translationem ita quosdam per Esaiam graui exprobratione Dominus increpitat dicens...

53. E. Bons et al. (éd.), La Bible d'Alexandrie, 23. Les douze prophètes, 1. Osée, Paris, 2002, p. 163-164: D. BARTHÉlemY (éd.), Critique textuelle de l'Ancien Testament, 3, FribourgGöttingen, 1992, p. 621.

54. La Bible d'Alexandrie, 23.1, p. 36.

55. R. GRYSON (éd.), Vetus Latina. Die Reste der altlateinischen Bibel, 12. Esaias, p. 1116. 
- Is 55, 6 reproduit la syntaxe du texte grec: at ubi appropinquauerit ouvre une

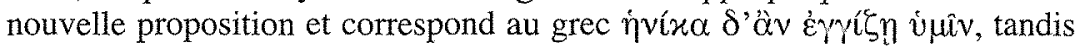
que dum prope est est rattaché à ce qui précède dans la traduction de Jérôme.

- Ez 33, 12 a salus esse, ce qui traduit le grec $\sigma \omega \theta \hat{\eta} v \alpha u$, alors que la Vulgate a uinere in iustitia sua.

- on peut opposer pour Jr 8, 6 Paen (defecit qui currit cursu suo, sicut equas

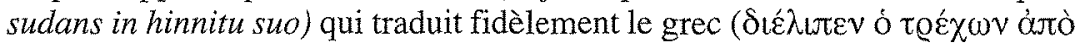

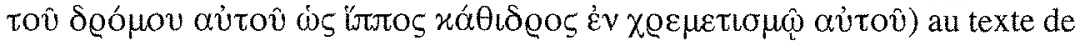
la version hiéronymienne sur l'hébreu (omnes conuersi sunt ad cursum suum quasi equus impetu uadens in proelio).

- dans So 2, 3, les différences entre la version latine d'après les LXX (respon-

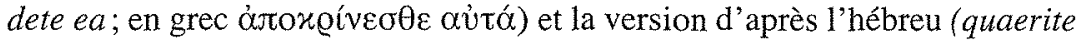
mansuetum) entraînent deux interprétations différentes que donne Jérôme dans son commentaire sur Sophonie, II, 3-456.

Ces exemples suffisent à montrer que, pour les prophètes, le texte de Paen représente une ancienne version latine qui repose sur le texte des LXX. Le cas du Siracide est particulier dans la mesure où le texte devenu vulgate est une ancienne version latine. Pour les versets tirés des Actes des apôtres, des Épîtres pauliennes et de l'Apocalypse, l'analyse montrera que, là encore, le texte de Paen présente des différences avec la Vulgate.

\section{2) Analyse du texte}

Par le biais de rapprochements avec les manuscrits bibliques et les citations patristiques, et en tenant compte du nombre d'attestations pour chaque verset, il est possible d'essayer de préciser le type de texte utilisé par Paen pour chacun des livres bibliques. L'ensemble constitué d'Ézéchiel et des Petits Prophètes permet de formuler quelques hypothèses ${ }^{57}$.

\section{Ézéchiel}

Les six extraits d'Ézéchiel ( $\mathrm{n}^{\circ \mathrm{s}} 25$ à 30 ) représentent quinze versets. Certains d'entre eux coïncident parfaitement avec d'autres attestations, ce qui n'est pas toujours le cas pour les citations de Paen.

56. M. HARL et al., La Bible d'Alexandrie, 23. Les douze prophètes, 4-9. Joël, Abdiou, Jonas, Naoum, Ambakoum, Sophonie, Paris, 1999, p. 350.

57. Les textes ne sont pas cités dans l'ordre, car nous traitons d'abord les livres les mieux représentés - qui paraissent donc plus significatifs; le numéro en gras renvoie à la numérotation introduite dans l'édition donnée p. 132-138. Cette étude s'appuie sur les volumes publiés par le Vetus Latina Institut de Beuron (Is, Si, 2 Tm et Ap). Pour les autres livres bibliques, nous avons en recours au fichier numérisé des attestations. Pour les citations patristiques, nous avons utilisé les éditions critiques les plus récentes. Les mots en romain dans une citation indiquent les divergences principales par rapport à Paen. 
25. Ez 33, 12. Seuls les derniers mots du verset sont cités. Le texte le plus proche se lit dans les restes d'une Bible copiée à Saint-Gall au IX ${ }^{e}$ s. et dont les fragments sont actuellements partagés entre Saint-Gall, Stiftsbibliothek 1398b p. 126-175 et Zurich, Zentralbiblitohek C 184, fr. 23 et 24. Ce manuscrit (désormais VL 176 ${ }^{58}$ ) comportait une version vieille latine d'Ézéchiel, de Daniel et des Petits Prophètes. VL 176 (éd. Dold): Et iustus non poterit saluus fieri in die peccati sui. L'ajout in die peccati figure dans la plupart des témoins de la recension origénienne ${ }^{59}$.

Ez 33, 13-14. Pour le v. 13, le texte le plus proche est VL 176 (éd. Dold): Cum iusto dicam ego: sicut uita uiues et ipse confidit super iustitiam suam et faciat iniquitatem omnis iustitiae eius non commemorabantur [-buntur post correctionem] in sua iniquitatem quam fecit in ea morietur. Ez 33, 14 est cité de manière identique dans VL 176.

Ez 33, 15-16. Sur les vingt-quatre citations du fichier numérisé du Vetus Latina Institut, seul un tout petit nombre a le v. 15 en entier. La coïncidence est pratiquement parfaite avec VL 176 (qui lit debitoris au lieu de debitori, et uiuit au lieu de uiuet). Quelques mots se lisent également dans VL 175 (ne faciat inicum uita uiuet et non morietur; éd. Dold). Le sigle VL 175 désigne les fragments d'un manuscrit biblique dont le texte est étroitement apparenté à VL 176. Sans doute écrit en Italie du Nord au $\mathrm{V}^{\mathrm{e}} \mathrm{s}$., le manuscrit a été démembré et utilisé dans des reliures; les fragments conservés sont partagés entre plusieurs bibliothèques ${ }^{60}$. Debitori/-ris, que l'on trouve aussi dans le texte de Cyprien (Ad Quirinum, III, 48), caractérise le texte antiochien ${ }^{61}$. Le v. 16 se lit sous la même forme dans VL 176 (à l'exception de uiuit au lieu de uinet).

26. Ez 17, 24. Paen est identique à VL 175. Le Speculum pseudo-augustinien $(76 ; 114)$ cite un texte proche, mais lit reuirescere, plus conforme au texte grec ( $\dot{\alpha} v \alpha \theta \alpha \dot{\lambda} \lambda \omega v)$, là où VL 175 et Paen ont reuiuiscere.

27. Ez 33, 10. Paen est identique à VL 175 et VL 176; moyennant pour ces deux manuscrits la correction de non tabescimus, fautif, en nos tabescimus.

Ez 33, 11 est proche de VL 175 et 176, sauf pour la fin du verset où les deux manuscrits diffèrent entre eux. VL 175: Propter hoc dic illis uiuo ego dicit dominus si uolo mortem impii quam ut reuertat se impius a sua via et uiuere eum;

58. Il est désigné sous le numéro 176 dans H.J. FREDE - R. GRYSON, Altlateinische Handschriften-Manuscrits vieux latins. Répertoire descriptif. Première partie, mss $1-275$, Freiburg, 1999, p. 270-271. Le texte est édité dans A. DoLD, Konstanzer altlateinische Propheten- und Evangelienbruchstücke mit Glossen nebst zugehörigen Prophetentexte aus Zürich und St. Gallen, Beuron, 1923.

59. J. ZIEGLER (éd.), Septuaginta: Vetus Testamentum Graecum, XVI, 1. Ezechiel, Nachtrag und corrigenda zur 1. Aufl, von 1952 von D. Fraenkel, Göttingen, 1977, p. 248.

60. Description et bibliographie dans H.J. FREDE - R. GRYSON, Altlateinische HandschriftenManuscrits vieux latins, p. 267-269.

61. J. ZrEGLER (éd.), Septuaginta: Vetus Testamentum Graecum, XVI, 1. Ezechiel, p. 248. 
VL 176: Propter hoc dic illis : uiuo ego dicit dominus si uolo mortem impii quam ut auertat se impius a sua uia et uiuat. Les éditeurs de Paen ont voulu corriger le uolo des manuscrits en nolo. Miodoński proposait également de supprimer le si. Cependant, la formule uiuo ego, dicit dominus, si uolo est attestée non seulement dans VL 175 et 176, mais aussi par Filastre de Brescia, Diuersarum hereseon liber, 82 (éd. Heylen): Vivo ego, dicit dominus; si uolo mortem peccatoris, quantum ut reuertatur et uiuat? L'éditeur considère apparemment si comme introduisant une interrogation directe. On peut cependant interpréter et ponctuer autrement. Dans les formules de serment (iuro si, uiuo si), la proposition introduite par si prend une valeur négative ${ }^{62}$. Il n'est donc pas nécessaire de corriger le texte qui signifie bien, de manière solennelle, que Dieu ne veut pas la mort de l'impie.

28. Ez 36, 36. Le verset est peu cité (sept attestations dans le fichier du Vetus Latina Institut). On ne dispose plus du témoignage des manuscrits VL 175 et 176, mais Tyconius, Liber regularum, 4, 3, 5, cite un texte pratiquement semblable (Tyconius emploie le féminin, demolitas ... exterminatas, là où Paen a le neutre).

29. Ez 18, 21. Deux auteurs dont les œuvres sont datées du début du ve s. ont un texte pratiquement identique à celui de Paen: Augustin dans le Contra secundam Iuliani responsionem imp. opus, III, $38^{63}$, et le De uita christiana, 2, que Jérôme attribuait à Pélage. Les deux auteurs ajoutent suis après iniquitatibus, et l'auteur du De uita christiana omet omnia. On trouve un texte très proche dans VL 176, dans la Didascalia apostolorum, 15, dans le Speculum pseudo-augustinien, 23, chez Fulgence de Ruspe, Ep. 7, 10 et Ad Euthymium, I, 10, 3, et chez Gildas le Sage, De excidio Britanniae, 61, 3. Toutefois, cette seconde série de textes se démarque des deux premières références et de Paen par l'omission de iudicium et. La séquence iudicium et iustitiam et misericordiam correspond au texte antiochien.

Ez 18, 22. L'auteur du De uita christiana, 2 et Fulgence, Ep. 7, 10 et Ad Euthymium, I, 10, 3 citent le même verset. VL 176, Augustin, dans le Contra Iulianum imp. opus, III, 38, l'auteur du Speculum, 23, la Didascalia apostolorum, 15, et Gildas, De excidio Britanniae, 61, 3 ont un texte quasi identique (uita uiuet au lieu de niuet).

62. A. BLAISE, Dictionnaire latin-français des auteurs chrétiens, Turnhout, 1954, s. v. uiuo; iuro; si.

63. Étudiant les citations d'un texte de peu antérieur, le De gratia et libero arbitrio, A.-M. LA BONNARDIĖRE, "Quelques remarques sur les citations scripturaires du De gratia et libero arbitrio", Revue des études augustiniennes, 9, 1963, p. 77-85, note que certaines citations bibliques suivent un autre texte ou apparaissent pour la première fois chez Augustin (certaines d'entre elles étant reprises dans le Contra Iulianum imp. opus). Les citations de ce traité témoignent d'une «nouvelle étape dans l'effort qu'il [Augustin] poursuivit toute sa vie pour mieux scruter l'Écriture» (p. 84), 
Ez 18, 23. Augustin, l'auteur du De uita christiana, la Didascalia apostolorum et Gildas ont là encore les textes les plus proches, mais la fin du verset est différente: et uiuere ei faciam dans le De uita christiana, et uiuat dans les autres cas. VL 176 et Fulgence attestent la même fin que Paen: et uiuere eum. Le début de la citation comporte toutefois quelques différences, p. ex. VL 176: Numquid uoluntate [m] uolo mortem peccatores [-ris post corr.] dicit dominus quam ut auertatur de uia sua mala et uiuere eum.

30. Ez 18, 30. Miodoński conjecture iniquitatis pour aligner le texte sur la LXX

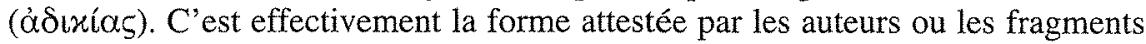
bibliques qui ont un texte identique à celui de Paen: le Speculum pseudo-augustinien, 23, Fulgence, Ad Monimum, I, 5, 3; iniquitatis est rétabli par les éditeurs de la version latine de la Didascalia apostolorum. C'est également la leçon de VL 176, mais elle est corrigée en iniquitates. Le texte de l'Ad Nouatianum, 18, montre que, anciennement, le mot a pu être interprété non comme un génitif mais comme un nominatif pluriel, sujet d'erunt (et non erunt uobis iniquitates uestrae ad poenam; éd. Diercks). Nous avons donc maintenu le texte des manuscrits.

Ez 18, 31. Le texte grec, ainsi que les témoins latins qui s'accordent avec Paen, laisseraient attendre impietates au lieu d'iniquitates: Didascalia apostolorum, 16; Ps.-Augustin, Speculum, 23, ainsi que VL 176. On trouve cependant chez Fulgence, Ad Monimum, I, 5, 3 (éd. Fraipont) la même particularité: Proicite a uobis omnes iniquitates uestras, quas impie fecistis aduersus me, et facite cor nouum et spiritum nouum.

Ez 18, 32. Les variantes pour ce début du verset 32 sont peu significatives. On notera seulement que Paen est identique au texte cité par Augustin dans le $D e$ gratia et libero arbitrio, XV, 31, et très proche de la Didascalia apostolorum, 16.

L'analyse des versets d'Ézéchiel permet les conclusions suivantes. (a) Les citations $25,26,27$ (c'est-à-dire les versets du chapitre 33 et celui du chapitre 17) sont identiques aux citations de deux manuscrits vieux latins étroitement apparentés: VL 175 et VL 176. (b) Les spécialistes considèrent que, pour Ézéchiel, leur texte est très proche de celui de Tyconius ${ }^{64}$. Dans le cas de Paen, la comparaison avec Tyconius n'est possible que pour l'extrait $n^{\circ} 28$, précisément un passage pour lequel on ne dispose plus du témoignage des manuscrits bibliques. Or les deux citations coïncident, à ceci près que Tyconius a le féminin, demolitas et exterminatas et Paen le neutre. (c) Reste le cas des versets tirés d'Ez 18. On discerne des liens avec un ensemble de textes: le Contra Iulianum imp. opus d'Augustin, le De uita christiana, ainsi que la version latine de Didascalie des apôtres, Fulgence, Gildas le Sage. Paen témoignerait donc d'un texte africain récent, qui a circulé - il est disponible en Italie (VL 175), en Grande-Bretagne (Gildas le Sage ${ }^{65}$ ) - et que l'on pouvait encore copier à Saint-Gall au IX $\mathrm{e}$.

64. H. J. FREDE - R. GRYSON, Altlateinische Handschriften-Manuscrits vieux latins, p. 268.

65. Selon F. C. BURKITT, «The Bible of Gildas », Revue Bénédictine, 46, 1934, p. 208, si Gildas 


\section{Les Petits Prophètes}

Paen reprend quatre versets de Michée, trois versets de Sophonie, un verset de Zacharie et deux versets d'Osée.

32. Mi 7, 2-3. Le texte selon les LXX que cite Jérôme dans son commentaire sur Michée est très proche de Paen, In Michaeam, II, VII, 1-4 (éd. Adriaen): Vae mihi, anima, quia periit reuerens de terra, et qui corrigat in hominibus [cité inter homines dans le commentaire] non est; omnes in sanguine iudicantur, unusquisque proximum suum tribulat tribulatione, in malum manus suas praeparant. De même dans ses Commentarii in epistulam ad Ephesios, II, 4 (PL 26, 546 C): Heu mihi, anima, quia periit reuertens [al. reuerens] a terra. Et qui corrigat, inter homines non est: omnes in sanguine iudicantur; ou lorsqu'il traduit Origène (homélies sur Ézéchiel, Hom. 1, 5; homélies sur Jérémie, Hom. 11). Cette version des versets 2-3 est très proche de celle de VL 17666. Le v. 2 est également attesté par Rufin dans sa traduction des homélies d'Origène sur les Nombres, Hom. 23, 2, 5 (quoniam periit reuerens a terra, et qui corrigat in hominibus non est; éd. Baehrens) et par Pélage, In Rom., 8, 23 (pour le v. 2). Il existe également des attestations plus tardives: Gildas, De excidio Britanniae, 86, 4 (Heu me, anima quia periit terrenis operibus, semper peccatorum reuerentia exoritur ${ }^{67}$ reuerens a terra, et qui corrigat inter homines non est. Omnes in sanguinem iudicio contendunt, et unusquisque proximum suum tribulatione tribulauit, in malum manus suas praeparat; éd. Winterbottom); une ancienne traduction d'une homélie de Basile, Hom. 1, 3 (quia perit reuerens a terra, et qui corrigat in hominibus non est); le huitième concile de Tolède en 653 (Eheu mihi anima, quia perit et reuertens ad terram, et qui corrigat inter homines non est, omnes in sanguine iudicatur; unusquisque proximum suum tribulat tribulatione; in malum manus suas praeparant; éd. Vives).

33. Mi 7, 8-9. Pour le v. 8, le point de comparaison le plus pertinent est VL 176: Noli supergaudere mihi inimica mea quia cecidi; sed resurgam; quia et si in tenebris ambulauero dominus lucebit mihi. La forme noli gaudere super me se lit chez Ambroise, Explanatio XI psalmorum, 37, 47, 3 ou 40, 34, 2, mais la citation s'arrête après resurgam ${ }^{68}$. Le début du v. 8 est également le texte attesté dans la série A (vieille latine) de capitula bibliques ${ }^{69}$. Le v. 9 est identique dans VL 176, chez Ambroise (Ep. 70; De paenitentia, II, 78), mais aussi chez Rufin, traducteur

cite un texte Vulgate pour Isaie et Jérémie, les Petits Prophètes et Ézéchiel ont un texte vieux latin qui s'accorde avec les fragments de Saint-Gall (VL 176).

66. Mais la fin du v. 2 est restituée à partir de Gildas, cf. A. DOLD, éd. citée, p. 279.

67. Ces mots sont considérés par F.C. BURKIT, art. cit., p. 208, comme une glose passée dans le texte.

68. Dans son De paenitentia, II, 8, Ambroise cite les v. 8-9 sous une forme proche de VL 176.

69. Biblia Sacra iuxta Latinam uulgatam uersionem, 17. Liber duodecim prophetarum ex interpretatione sancti Hieronymi, Romae, 1987, p. 56. 
des homélies de Basile (Hom. 5, 5), et chez Jérôme, lorsqu'il cite d'après les LXX, par exemple dans ses commentaires, In Michaeam, II, VII, 8-13; In Isaiam, XVIII, 66; In Hiezechielem, V, XVII, 19-21; XIV, XLVII; ou dans ses traductions d'Origène (par exemple dans l'homélie 10, 4 sur Ézéchiel).

34. So 2, 1. Sur les douze attestations du fichier du Vetus Latina Institut, le texte le plus proche est VL 176. Toutefois, là où Paen a precamini, VL $176 \mathrm{a}$ conligamini. Conligamini est également le texte de Jérôme lorsqu'il cite les LXX, par exemple dans son commentaire sur Sophonie, II, 1-2 (éd. Adriaen): Congregamini et collegamini, gens inerudita. Jérôme glose le texte traduit de l'hébreu (congregamini) et le verbe traduit du grec (colligamini) de la manière suivante : estote uobis, iuxta apostolum [cf. Ep 4, 3], caritatis uinculo copulati et plus bas sociamini uobis

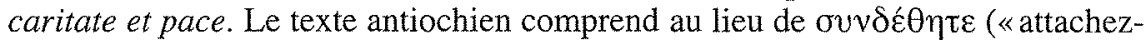

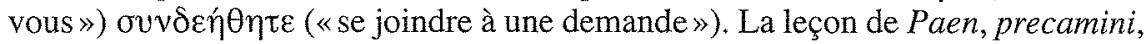
repose très clairement sur la variante antiochienne, que commente Théodore de Mopsueste pour la rejetter ${ }^{70}$. Le seul autre témoignage latin que l'on puisse alléguer est donné par les capitula vieux latins: Depraecamini gens indisciplinata ${ }^{71}$. Deprecamini est aussi la leçon de $P$ après correction. C'est l'un des cas où l'on peut hésiter entre $G H$ et $P$. La correction de $P$ peut-elle avoir été influencée par cette série de capitula?

So 2 , 2. Le nombre d'attestations est réduit. Le début du verset, jusqu'à ira Domini, est cité à l'identique par Gildas, De excidio Britanniae, 55. Pour l'ensemble du verset, le texte le plus proche est celui du Speculum pseudo-augustinien, 5 (éd. Weihrich) : prius quam efficiamini sicut flos praeteriens prius quam superueniat super uos dies iracundiae Domini ${ }^{72}$. La traduction de Jérôme d'après les LXX présente des différences plus grandes, In Sophoniam, II, 1-2 (éd. Adriaen): antequam sitis sicut flos pertransiens diem, antequam ueniat super uos ira Domini, antequam super uos irruat dies irae furoris Domini.

So 2, 3. Le v. 3 rappelle le texte que cite Jérôme d'après les LXX, In Sophoniam, II, 3-4 (éd. Adriaen): Quaerite Dominum, omnes humiles terrae, iudicium operamini, et iustitiam quaerite et respondete ea, ut protegamini in die irae Domini. Le Speculum pseudo-augustinien, 5, Lucifer de Cagliari, Qui absentem nemo debet iudicare nec damnare, I, 36 et VL 176 ont également des textes apparentés. Ces quatre auteurs présentent toutefois une différence importante par rapport au texte

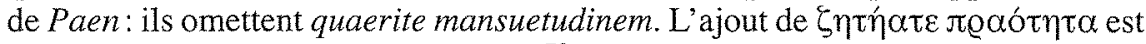
une caractéristique du texte antiochien ${ }^{73}$, que traduit donc ici Paen.

70. La Bible d'Alexandrie, 23. Les douze prophètes, 4-9, p. 349.

71. Biblia Sacra, 17, p. 58.

72. VL 176 est en partie illisible (priusquam fias ... p... superueniat super uos ...); A. DoLD, éd. cit., p. 275 et 280, restitue son texte par comparaison avec le Speculum pseudo-augustinien.

73. J. Zregler, Septuaginta: Vetus Testamentum Graecum, XIII. Duodecim prophetae, Göttingen, $1984^{3}$, p. 278; La Bible d'Alexandrie, 23.4-9, p. 350. 
35. Za 1, 3. Le texte est trop court et ses très nombreuses attestations présentent des différences trop minces pour qu'il soit possible de classer notre extrait. On remarquera cependant que le manuscrit $P$, qui ajoute et ego, tend à aligner une fois encore le texte de Paen sur les capitula vieux latins ${ }^{74}$. VL 176 n'a que le début du verset: conuertimini ad me dicit dominus uirtutum.

36. Os 14, 2. C'est le texte de Jérôme d'après les LXX, In Osee, III, XIV, 2-4 (mais Jérôme a quia au lieu de quoniam). VL 175 et 176 ont reuertere au lieu de conuertere, et propter quod au lieu de quoniam.

Os 14, 3. Paen s'accorde avec VL 175 et VL 176 (éd. Dold): Adsumite uobiscum multos et conuertimini ad dnm dm uestrum (et) dicite illi; potens es dimittere peccata; ita ut non accipiatis iniquitatem sed ut accipiatis bona; le Speculum pseudo-augustinien, 23 (éd. Weihrich) cite le même verset sous une forme abrégée: Sumite uobiscum multos et conuertimini ad dominum deum uestrum. Dicite illi : potens est dimittere peccata ut accipiatis bona. L'ajout de potens es dimittere peccata est une caractéristique du texte antiochien 75 . Paen cependant se distingue de ces trois citations par l'ajout d'adorantes qui n'a pas d'attestation en grec.

Les citations de Paen concordent avec Jérôme lorsqu'il cite la Bible d'après les LXX, avec l'auteur du Speculum pseudo-augustinien, Lucifer de Cagliari et Ambroise. Nous avons régulièrement rapproché Paen de VL 176 et 175. Les spécialistes considèrent que, pour les Petits Prophètes, ces deux manuscrits conservent un texte italien ${ }^{76}$. Paen offre également des leçons qui isolent son texte au sein de la tradition latine (So 2,$1 ; 2,3$ ): elles correspondent le plus souvent au texte antiochien. Paen offre donc un texte apparenté à celui des manuscrits bibliques VL 175 et 176, mais qui témoigne d'une révision sur le grec. Gildas et le VIII concile de Tolède témoignent de la diffusion de ce type de texte.

En comparant VL 175 et 176 d'une part et Paen de l'autre, M. Stenzel était déjà arrivé à la conclusion que l'auteur de Paen avait utilisé un manuscrit qui corrigeait le texte d'origine de VL 175 et VL $176^{77}$, mais il attribuait à des initiatives personnelles de l'auteur certaines particularités du texte biblique. Notre étude montre toutefois que la plupart de ces variantes sont attestées par ailleurs: conuertere (Os 14,2) est le texte de Jérôme; noli gaudere (Mi 7,8) est cité par Ambroise ; efficiamini (So 2,2) correspond au texte du Speculum pseudo-augustinien et de Gildas le Sage; ueniat se trouve chez Gildas; protegamini se trouve dans le Speculum, 5.

74. Biblia Sacra, 17, p. 59 .

75. J. ZIEGLER, Septuaginta: Vetus Testamentum Graecum, XIII. Duodecim prophetae, p. 179; La Bible d'Alexandrie, 23. 1, p. 164.

76. H. J. FREDE et R. GRYSON, Altlateinischen Handschriften-Manuscrits vieux latins, p. 268; M. STENZEL, art. cit., p. 42.

77. M. STENZEL, art. cit., p. 73-84. 
VL 175 et 176 constituent un point de référence récurrent pour les citations d'Ézéchiel et des Petits Prophètes. Selon les spécialistes, ces deux manuscrits n'ont pas un texte homogène: si le texte d'Ézéchiel est proche de Tyconius, celui des Petits Prophètes rappelle Lucifer de Cagliari. Au-delà des rapprochements ponctuels avec ces manuscrits vieux latins, Paen a un point commun plus général avec eux : il témoigne de la même hétérogénéité.

Daniel

Avant d'examiner les citations d'Isaïe et de Jérémie, pour lesquelles le témoignage de VL 175 et 176 fait défaut (Isaïe et Jérémie sont transmis selon la Vulgate dans VL 176), il faut dire un mot des deux versets de Daniel. En effet, ces deux versets figurent également dans VL 176 selon une ancienne version.

31. Dn 4, 34 LXX. Les points de comparaison pour ces deux versets sont peu nombreux. VL 176 offre le texte le plus proche, mais il y a des différences notables: $E t$ post finem dierum ego nabuchodonosor oculos meos in caelum sustuli et sensus mei in me conuersi sunt et excelsum deum benedixi et uiuentem in saeculum laudaui quoniam potestas eius sempiterna est et imperium eius in saecula et saecula. Une double expression altissimum laudaui et regem caeli benedixi traduit le grec $\tau \hat{\omega}$

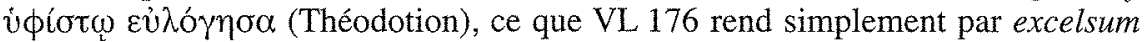
deum benedixi. La deuxième partie de l'expression, regem caeli benedixi, semble

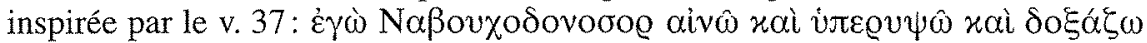

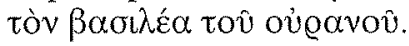

Dn 4, 35 LXX. La traduction de VL 176 est un peu différente là encore: omnes qui habitant in terra[m] ut nihil habiti sunt.

Isaïe

Paen cite sept extraits d'Isaie, qui représentent dix-sept versets. Dans le volume de la Vetus Latina édité par R. Gryson ${ }^{78}$, les citations de Paen sont rattachées à la forme $\mathrm{C}$ du texte, c'est-à-dire à une forme africaine plus récente que le texte de Cyprien. À quatre exceptions près (Is 30,$1 ; 30,15 ; 44,21$ et 22 ), Paen est toujours utilisé comme référence pour cette forme de texte. Pour huit versets, il n'y a pas de forme plus ancienne du texte que la forme $\mathbf{C}$ attestée par Paen (Is 31 , $6 ; 46,8-9 ; 54,7-8 ; 57,15.20-21)$.

2. Is 30,15 . Paen cite un texte européen, identique à celui du Speculum pseudoaugustinien ou de Lucifer de Cagliari par exemple.

3. Is 30,1 . Le texte de Paen correspond à celui qui fut cité lors du huitième concile de Tolède iuxta ueterem translationem. Les deux citations ont en commun des variantes particulières que l'éditeur de la Vetus Latina d'Isaïe répertorie tantôt comme variante du texte africain (desertionis) tantôt comme variante du texte européen (sponsionem). La forme adicere est un point de contact avec la forme 
africaine du texte (adponendo pour le texte européen, ut adderetis pour la version iuxta LXX citée par Jérôme, et ut adderetur pour la traduction sur l'hébreu).

5. Is 31,6. Le verset est peu cité. C'est 1'un des cas où Paen sert de référence pour la forme $\mathbf{C}$ du texte et où l'on ne dispose pas d'attestation pour le type africain ancien. Paen atteste seul la variante altam cogitationem. On peut voir dans le choix de cogitationem cogitatis le souci de respecter la figure étymologique du

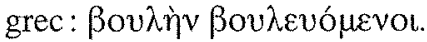

6. Is 43, 25-26. Paen présente deux leçons notables: iniustitias tuas dans les deux versets pour rendre le grec tà $\alpha^{2}{ }^{2} \mu u_{\alpha} \varsigma$ oov, et recordare au v. 26 là où le grec a $\mu v \eta ́ \sigma \theta \eta t \imath$. La version latine de Paen semble se caractériser par un souci de plus grande confirmité au texte grec: recordare au v. 26 permet de traduire le même mot grec par le même mot latin. Prius est considéré par R. Gryson comme caractérisant la forme africaine ancienne du texte $(\mathbf{K})$. Le texte le plus proche de celui cité par Paen date de la fin $\mathrm{V}^{\mathrm{e}} \mathrm{s}$. : il s'agit de 1'homélie 9 du manuscrit de Vérone, Bibl. cap. LIX (57): Ego sum qui deleo iniustitias tuas et non recordabor. Tu autem recordare; dic tu iniustitias tuas primus ut iustificeris (Hom. 9, 3; éd. Sobrero).

7. Is 55, 6-7. Misericordia ei praestabitur (v. 7) se lit chez Chromace, Tractatus in Matthaeum, 33, 4. Il y a aussi des points de contact avec le texte africain ancien

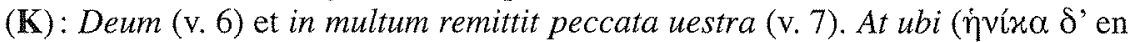
grec) isole Paen des autres témoignages patristiques.

8. Is 44, 21-22. Il s'agit de deux des quatre versets pour lesquels Paen ne sert pas de référence pour $\mathbf{C}$; l'éditeur de la Vetus Latina dispose en effet du témoignage de Tyconius, Liber regularum (éd. Burkitt), II, 6: Finxi te puerum meum, meus es tu Israhel, noli obliuisci mei. Ecce enim deleui uelut nubem facinora tua et sicut nimbum peccata tua. Conuertere ad me et redimam te. Les points de contact entre les deux auteurs sont significatifs. La citation de Paen comporte également plusieurs leçons singulières. Vocaui est expliqué par R. Gryson comme une influence d'Is 43, 179. Abstersi (Tyconius: deleui) et iniustitias tuas (Tyconius: facinora tua) sont également propres à Paen. Iniustitias correspond là aussi au

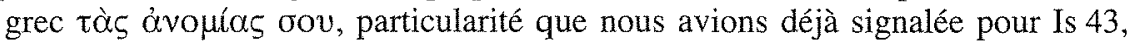
25-26. Seul Hilaire, Tractatus super psal. 118, daleth, 10, présente à cet endroit la même leçon (éd. Doignon - Demeulenaere): Ecce deleam ut nubem iniustitias tuas et tamquam nebulam peccata tua.

9. Is 46, 8-9. Pour ces deux versets, R. Gryson oppose Paen, texte africain récent, au manuscrit VL 177, qui représente le type européen ${ }^{80}$. Les deux textes ne se rejoignent que sur conuertimini corde. Parmi les leçons singulières de Paen, deux

79. R. GRYSON, Vetus Latina. Die Reste der altlateinischen Bibel, 12. Esaias, p. 1053.

80. Wurzbourg, Universitätsbibliothek, Mp. th. f. 64a (palimpseste; $v^{\mathrm{e}} \mathrm{s}$. pour le texte des prophètes), bibliographie dans H. J. Frede et R. Gryson, Altlateinische Handschriften-Manuscrits vieux latins, p. 272-273. 
méritent une mention particulière. Paen ajoute ad me après conuertimini corde. Cet ajout n'a pas d'équivalent dans la tradition latine ou grecque. Doit-on supposer l'influence d'un autre texte prophétique, comme Jl 12, 2 (conuertimini ad me in toto corde uestro), très proche, souvent cité sur le même thème et même associé à Is 46, 8-981 ? Faut-il y voir plutôt une intervention du compilateur influencé par les autres citations qu'il a sélectionnées? Conuertere ad me apparaît en effet dans l'extrait précédent (Is 44,22). Priora saecula découle peut-être, par haplographie, de la leçon attendue priora a saeculo ${ }^{82}$.

10. Is 54, 7-8. Par rapport à d'autres versets d'Is cités par Paen, les v. Is 54, 7-8 sont peu attestés. Le texte de Paen semble se caractériser par un souci de fidélité au grec: par exemple l'adjectif $\mu$ xoòv dans les v. 7 et 8 est traduit par le même mot latin, pusillo, traduction au demeurant propre à Paen.

11. Is 57, 15. Paen se distingue peu du texte européen (ajout de est après nomen;

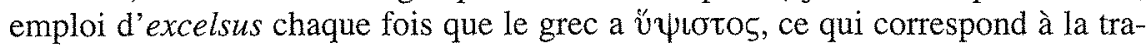
duction selon les LXX de Jérôme; dans uitam, ce qui correspond à l'un des textes d'Augustin).

Is 57,16 . Le texte $\mathrm{C}$, représenté par Paen, a un point commun avec les textes africain ancien et européen: ils supposent un modèle grec -- ou un ancêtre latin

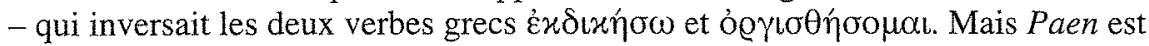
souvent isolé par rapport aux autres attestations latines (per omnia, qui semble

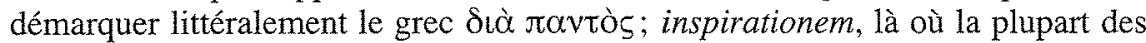
autres versions s'accordent sur flatum). Paen partage prodiet avec l'un des textes d'Augustin, Enarrationes in Psalmos, in Ps 42, 3 (éd. Dekkers - Fraipont): Spiritus, inquit, a me prodiet.

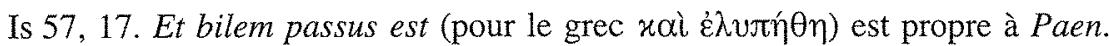
Augustin, De Genesi ad litteram, VII, 3 (éd. Zycha), ne cite que le début du verset, sous une forme identique à celle de Paen: Et propter peccatum, inquit pusillum quid contristaui et percussi eum.

Is 57, 18. Le texte de Paen correspond à la forme européenne du texte.

Is 57,19 . On notera que sanaui (sanabo dans le texte européen et dans la traduction de Jérôme selon les $\mathrm{LXX}$ ) correspond à la traduction de Jérôme d'après l'hébreu.

Is 57, 20. Le verset 57, 20 n'est pratiquement jamais cité. Outre Paen, on ne peut alléguer dans le domaine latin que le commentaire de Jérôme sur Isaïe, XVI, 13. R. Gryson mentionne également les gloses de deux manuscrits espagnols de la Vulgate, VL 94 et VL 95, mais elles sont extraites du commentaire de Jérôme et ne contribuent donc pas à élargir notre connaissance des versions latines pour

81. Ps.-CYPrIEN, Ad Nouatianum, 9, et JÉRôME, Ep. 122, 2.

82. R. GRYSON, Vetus Latina. Die Reste der altlateinischen Bibel, 12. Esaias, p. 1116; voir aussi p. 100 . 
ce verset ${ }^{83}$. À cet égard, le témoignage de Paen est important. Dans le domaine grec, la moisson n'est guère plus abondante, et ce sont surtout les auteurs de commentaires exégétiques qui citent le verset ${ }^{84}$. Le texte cité par Paen diffère de celui de Jérôme d'après les LXX (qui autem iniqui sunt, fluctuabunt, et quiescere non poterunt) et d'après l'hébreu (impii autem quasi mare feruens quod quiescere non potest). Paen repose sur la recension lucianique du texte grec, comme le

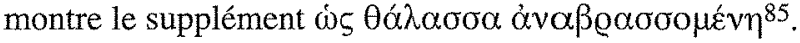

Is 57, 21. Paen cite le texte européen, du Speculum augustinien et de Lucifer de Cagliari.

L'étude verset par verset aboutit aux conclusions suivantes. (a) Paen cite des versets pour lesquels on n'a parfois que peu d'attestations; malgré sa brièveté, Paen permet donc d'enrichir notre connaissance des anciennes versions latines de certains versets d'Isaie. (b) Lorsqu'il y a assez d'éléments de comparaison, on note des points de contacts indéniables avec des variantes attestées dans le texte africain ancien $(\mathbf{K})$ ou plus récent $(\mathbf{C})$; cela s'accompagne d'une influence perceptible de traits européens ${ }^{86}$. (c) Beaucoup de leçons paraissent isolées, ce qui rend Paen difficile à situer; mais cette «singularité » n'est peut-être que la conséquence d'une information lacunaire. Il nous a semblé qu'elle venait parfois d'un souci de mieux se conformer au texte grec: la traduction de per omnia en Is 57,16 ; la traduction systématique de ávouí $\alpha$ par iniustitia (Is 43, 25-26 et 44,22 ). Dans certains cas, c'est le verset en entier qui présente un vocabulaire différent des autres versions connues (Is 46, 8-9), ce qui justifie d'y voir une forme particulière du texte.

Jérémie

Aux onze extraits de Jérémie - seize versets -, il faut ajouter trois extraits des Lamentations, attribuées à Jérémie - soit sept versets. Les citations sont plus rares que celles que nous avons examinées jusqu'à présent, et cette base étroite de comparaison explique qu'il soit plus difficile de caractériser le texte. Dans le fichier numérisé du Vetus Latina Institut de Beuron par exemple, les versets de Paen sont parfois attestés par une demi-douzaine de citations seulement.

4. Jr 2, 25. Le texte le plus proche se lit chez Lucifer de Cagliari, De non conueniendo cum haereticis, 8 (éd. Diercks): Auerte pedem tuum ab aspera uia et faucem tuam a siti. Quae autem dixit: confortabor, quia dilexit exteros et post

83. R. GRYSON, Vetus Latina. Die Reste der altateinischen Bibel, 12. Esaias, p. 811.

84. Quatre références seulement dans la base Biblindex (avril 2009): Pierre d'Alexandrie, Epistula canonica, 4 ; Eusèbe de Césarée, Commentarii in Esaiam, II, 46; Théodoret de Cyr, Sur le prophète Isaïe, 57, 20; Procope de Gaza, Catena in Esaiam, 2.

85. J. ZIEGLER, Septuaginta: Vetus Testamentum Graecum, XIV. Isaias, Göttingen, 1983³, p. 336.

86. Sur la distinction appliquée au texte d'Isaï, voir R. GRYSON, Vetus Latina. Die Reste der altlateinischen Bibel, 12. Esaias, p. 1651-1653. 
illos abibat. Le texte cité par Jérôme d'après la LXX offre aussi des ressemblances pour le début du verset: Commentarii in Isaiam, XVI, 7 (confortabor est donné

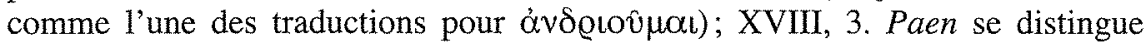
toutefois par l'ajout de nolo. Le texte a gêné Miodoński qui propose la conjecture confortari nolo. En réalité, confortabor nolo correspond au texte antiochien ${ }^{87}$.

12. Jr 2, 32. Deux variantes isolent Paen des autres attestations du verset dans le fichier numérisé de Beuron (cinq citations seulement pour la fin du verset). Dierum calque le texte antiochien autres versions latines ont innumeris, démarque également la syntaxe du grec.

13. Jr 18,7-10. Les v. 7-8 sont cités une trentaine de fois, les v. 9-10 une quinzaine dans le fichier numérisé du Vetus Latina Institut de Beuron. Le texte le plus proche est celui que cite Hilaire dans ses Tractatus super psalmos, Ps 2, 39 (éd. Doignon): In summa loquar super gentem aut super regnum, ut feriam eos et perdam; et si conuersa fuerit gens illa a malis suis, paenitebo de malis, quae cogitabam facere illis. Et in summa loquar super gentem et regnum ut reaedificem et plantem. Et facient mala ante me, ut ne audiant uocem meam; et paenitebo de bonis quae locutus sum facere illis.

14. Jr 3, 12. Aucune des seize citations répertoriées ne reproduit le texte de Paen. Les premiers mots sont cités par Jérôme, Commentarii in prophetas minores. In Zachariam, I, II, $6 / 9$ (éd. Adriaen): Reuertere ad me, habitatio Israel, dicit Dominus. Certaines des variantes de Paen pour la suite sont également mentionnées par Jérôme dans le lemme de son commentaire sur Jérémie, I, 57 (éd. Reiter): reuertere, auersatrix Israhel, dicit dominus, et non auertam-siue firmabo-faciem meam a uobis - siue super uos -, quia sanctus - siue misericors - ego sum, dicit dominus, et non irascar in perpetuum. Le texte de l'Ambrosiaster, Quaestiones Veteris et Noui Testamenti, 102, 7 (éd. Souter) présente des similitudes: reuertimini ad me, commoratio Israhel, dicit dominus, et non firmabo faciem meam in uos, quia misericors ego sum, dicit dominus, nec irascor uobis in aeuum.

15. Jr 3, 14-15. On compte une vingtaine d'attestations pour le v. 14, mais aucune ne correspond exactement à Paen. Dans son commentaire sur Jérémie, I, 58, Jérôme cite plusieurs variantes de Paen: Conuertimini, filii reuertentes - siue uagi et recedentes -, dicit dominus, quia ego uir uester - siue dominabor uestri-, et adsumam uos, unum de ciuitate et duos de cognatione, et introducam uos in Sion. Elles figurent d'ailleurs dans sa traduction du Liber Orsiesii (éd. Boon, p. 131, 31 et 140,25$)$ : Reuertimini ad me, filii recedentes, et ego dominabor uestri (...). Tollam uos unum de populo et duos de familia, et inducam uos in Sion. Le v. 15 est plus souvent cité. Dans Paen, il est caractérisée par le terme disciplina pour

87. J. ZIEGLER, Septuaginta: Vetus Testamentum Graecum, XV. Ieremias, Baruch, Threni, Epistula Teremiae, Göttingen, 1976, p. 158.

88. J. ZIEGLER, Septuaginta: Vetus Testamentum Graecum, XV. Ieremias, Baruch, Threni, Epistula Teremiae, p. 159. 
rendre le grec des LXX غ̇ंıбtท́ $\mu \eta$. C'est une traduction fréquente, qu'on trouve chez Cyprien (Ep. 4, 1, 2; Ad Quirinum, I, 14), chez Lucifer de Cagliari (p. ex. Quia absentem nemo debet iudicare nec damnare, I, 2), chez Augustin (Contra Cresconium, III, 8, 8) et jusque dans la Règle du Maître, 1, 82.

16. Ir 3, 22 est cité de manière identique dans le De uita christiana, 2 . Jérôme cite parfois une forme proche, p. ex. Com. in Isaiam, VII, 27, 11: Conuertimini ad me, filii conuertentes, et ego sanabo contritiones uestras.

17. Jr 4, 14 est cité à l'identique dans Ps.-Augustin, Speculum, 23.

18. Jr 8, 4. Le v. 4 est fréquemment cité (cinquante-trois attestations), et beaucoup d'auteurs (Lucifer de Cagliari, Jérôme dans sa traduction des homélies d'Origène sur Ézéchiel) ont un texte voisin de celui de Paen. La citation la plus proche se trouve dans Ps.-Augustin, Speculum, 23 (éd. Weihrich): Haec dicit dominus: numquid qui cadet non resurget? aut qui auertit se non conuertetur? Le v. 5 est nettement moins attesté (dix-neuf occurrences). Le texte le plus proche est à nouveau cité dans le Speculum pseudo-augustinien, mais avec des différences sensibles dans la première partie de la citation: Quare conuertit populus iste conuersionem malignam, et tenuerunt praesumptionem suam et noluerunt conuerti? Auersio improba n'est utilisé que dans la traduction d'une lettre adressée par l'empereur Constantin IV au pape Léon II (682), mais il s'agit plus d'une allusion que d'une citation (PL 96, 397 D) : Quare auertis auersionem improbam, et detentus es in haeretico proposito tuo; et noluisti conuertere te ad pietatem?

19. Jr 8, 6. Cf. Ps.-Augustin, Speculum, 23 (éd. Weihrich): non est homo paenitentiam agens a malitia sua dicens : quid feci? defecit quia currebat a cursu suo, sicut equus sudans in hinnitu suo. Sur les quinze citations du fichier numérisé, seules sept ont la fin du verset.

20. Ir 18, 11-12. Seul le v. 11 est cité dans Ps.-Augustin, Speculum, 23, qui offre à nouveau un texte presque identique: Auertatur iam nunc unusquisque a uia sua mala, et meliora facite studia uestra. Il n'y a que huit attestations pour le verset 12. Certaines variantes de Paen sont mentionnées par Jérôme, In Hieremiam prophetam libri VI, IV, 3 (éd. Reiter; le v. 11 est assez différent): desperauimus - siue confortabimur -; post cogitationes enim nostras ibimus et unusquisque prauitatem - siue quod placuit cordi suo malo - faciemus. Le verset 12 appelle deux remarques supplémentaires. On attendrait malo, conformément au grec et à la variante que cite Jérôme. Toutefois, plutôt que de voir dans mala une erreur imputable à la transmission de Paen, nous avons préféré considérer qu'il s'agissait d'une faute remontant à la version latine utilisée dans le florilège. On

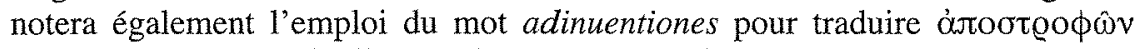
qui n'est pas attesté ailleurs. Les autres versions latines ont cogitationes. Lorsqu'adinuentiones est utilisé dans d'autres citations «vieilles latines», c'est

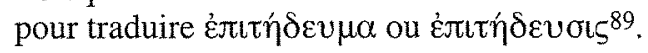

89. Par exemple, Jérôme cite adinuentionum comme variante de cogitationum pour $\mathrm{Jr} 4,4$ 
23. Jr 3, 6-7. Les citations les plus proches se lisent chez Jérôme dans sa traduction des homélies sur Jérémie d'Origène, Hom. 14 (PL 25, c. 687): Et dixit Dominus ad me in diebus regis Iosiae: Vidisti quid fecit mihi habitatio domus Israel ? (...) Abiit subtus omnem montem excelsum, et subtus omne lignum nemorosum, et fornicata est illic; ainsi que chez Gaudence de Brescia, Tractatus, 8, 37 (éd. Glück): Vidisti quae fecit mihi habitatio domus Israhel? Abiit super omnem montem excelsum et subtus omne lignum nemorosum et fornicata est illic in idolis; (...) Et dixi, postquam fornicata est haec omnia: reuertere ad me et non est reuersa. Gaudence et Jérôme dans ce texte sont les seuls auteurs latins à avoir habitatio domus Israel. Les éditeurs précédents de Paen ont choisi de supprimer domus, considéré comme une glose passée dans le texte. Le témoignage de Jérôme et de Gaudence incite pourtant à conserver le texte des manuscrits, malgré l'absence de parallèle en grec $^{90}$; les trois auteurs ont sans doute une source commune. Paen se distingue cependant avec le curieux texte subiit usque ad omne lignum nemorosum au lieu de subtus omne lignum nemorosum. Subiit est isolé dans la tradition latine et ne

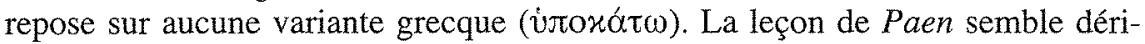
ver d'une mauvaise lecture ou d'une mauvaise compréhension de la préposition latine subtus. Plusieurs auteurs citent le v. 7 sous une forme très proche de Paen: Gaudence de Brescia, Tractatus, 8, 37 ; Ps-Ambroise, De paenitentia, 10 ; Jérôme, Ep. 122, 1, et dans sa traduction des homélies sur Jérémie d'Origène (Hom. 14).

21. Lm 2, 18. La fin du verset, non sileat pupilla oculi tui, parfois citée de manière isolée, se lit sous cette forme chez Ambroise, Expositio psalmi CXVIII, Litt. 17, 35 , et chez Jérôme (Ep. 122, 3 ; Commentarii in Isaiam, XIII, praef., par exemple).

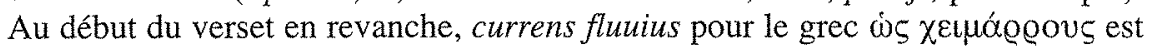
sans parallèle. On peut également se demander quelle leçon retenir pour ce qui correspond au grec ěxvๆ $\psi\lrcorner v^{91}$ : requiem, leçon de la Vulgate et des autres citations patristiques, leçon également attestée par les recentiores et $P$, ou bien requiescere, la leçon de $G H$ et de $M^{\text {ac }}$. Étant donné le caractère atypique du début du verset (effunde [deducldeducant dans les autres attestations du verset], currens fluuius), nous avons retenu requiescere.

22. Lm 3, 40-42. Pour les v. 40-41, le seul texte identique à Paen se trouve dans le Speculum pseudo-augustinien, 5 et 23. Et respiciamus ad Dominum qui habitat in caelis correspond au texte antiochien ${ }^{92}$. Pour le v. 42 (que ne cite pas le Speculum

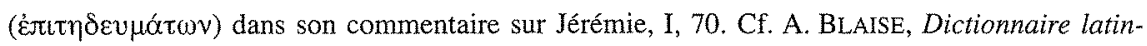
français des auteurs chrétiens, $s, u$. adinuentio; TLL, I, c. 688-689.

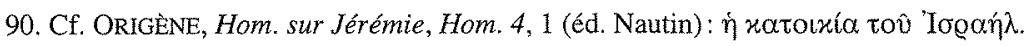

91. Sur ce substantif, voir I. Assan-Dhôte et J. MoATTI-Fine, La Bible d'Alexandrie, 25.2. Baruch, Lamentations, Lettre de Jérémie, Paris, 2005, p. 229.

92. J.ZIEGLER, Septuaginta: Vetus Testamentum Graecum, XV. Leremias, Baruch, Threni, Epistula Ieremiae, p. 484, mais les deux textes latins ont dominum, là où le grec a

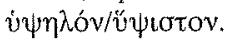


pseudo-augustinien), seules quatre autres attestations sont répertoriées dans le fichier du Vetus Latina Institut, et aucune n'a le même texte que Paen.

24. Lm 3, 31-33. Paen s'accorde avec les autres attestations «vieilles latines» connues de ces versets, par exemple Ambroise, De paenitentia, I, 5 et Expositio psalmi CXVIII, Litt. 11,2, et Ps.-Augustin, Speculum, 39 (pour les v. 31-32). Paen se distingue par l'usage du futur (humiliabit, repellet). Le v. 32 figure aussi sous cette forme dans le palimpseste de Wurzbourg, VL 177 (éd. Ranke) : quoniam cum humiliauerit iterum miserebitur secundum multitudinem misericordiae suae.

La principale difficulté que pose l'étude de l'ensemble «Jérémie» tient au faible nombre d'attestations pour certains versets. Les auteurs avec lesquels nous avons été amenée à faire des rapprochements sont Ambroise, l'auteur du Speculum pseudo-augustinien, auxquels on peut ajouter Lucifer de Cagliari et Gaudence de Brescia. Le texte cité par Paen est donc celui que citent aussi des auteurs italiens des $\mathrm{IV}^{\mathrm{e}}$ et $\mathrm{V}^{\mathrm{e}} \mathrm{s}$. Comme c'était déjà le cas pour les autres livres, on relève un nombre non négligeable de leçons singulières (ou du moins qui apparaissent comme telles au vu des attestations connues); certaines d'entre elles (p. ex. Jr 2, $25 ; 2,32)$ traduisent un souci de grande fidélité au texte antiochien.

Les citations que nous allons maintenant traiter paraissent moins significatives, parce que le nombre de versets cités est trop faible pour que l'on puisse caractériser le texte du livre en cause et/ou parce qu'il s'agit de livres bibliques pour lesquels la tradition latine est moins différenciée que pour les précédents.

\section{Ecclésiastique}

L'Ecclésiastique illustre justement ce dernier cas de figure. Paen cite la forme ancienne du texte devenue vulgate.

37. Si 17, 25.26-29 LXX. C'est la forme V du texte qui est citée. À deux reprises, l'extrait est abrégé (omission de et orationis [v. 26] et de et laudabis [v. 29]), sans doute à la suite d'un saut du même au même ${ }^{93}$. Ces versets comportent aussi deux variantes. Perit confessio (v. 27) est une leçon facilitante pour perit confiteberis uiuens $^{94}$, et c'est un texte qu'on lit également chez Augustin, dans les Enarrationes in psalmos et dans le Contra Cresconium, II, XXVI, 31. Propitiationis, au lieu de propositionis, est une leçon attestée également par la forme $\mathbf{Z}$, dont le principal représentant est le manuscrit $Z$, Metz, Bibl. mun. 7, peut-être sous l'influence du v. 28. La nature précise de ce type de texte est mal déterminée ${ }^{95}$.

93. W. THIELE, Vetus Latina. Die Reste de altlateinischen Bibel, 11/2. Sirach, Ecclesiasticus, Freiburg, 1987-, p. 503; 506.

94. W. THIELE, Vetus Latina. Die Reste de altlateinischen Bibel, 11/2. Sirach, Ecclesiasticus, p. 107.

95. W. THELE, Vetus Latina. Die Reste de altlateinischen Bibel, 11/2. Sirach, Ecclesiasticus p. $35 ; 136-137$. 
38. Si 20, 4. Le verset n'est pratiquement jamais cité, l'édition de W. Thiele ne répertorie que Defensor de Ligugé, Liber scintillatum, 9, 4.

Ps

1. Ps $88,31-34$. Le texte est différent du texte africain utilisé par Cyprien. Les leçons de Paen, très répandues, ne permettent de rapprocher de manière significative le texte cité d'une forme particulière du psautier. On remarquera simplement que, à l'exception du dernier mot ( $a b$ eis / $a b e o$ ), c'est le texte de la version iuxta $L X X$ de Jérôme.

Les extraits tirés du Nouveau Testament sont moins nombreux. Les Épîtres pauliniennes constituent l'ensemble le plus important. Les variantes entre les formes de textes sont moins nombreuses et moins grandes.

\section{Épîtres pauliniennes}

41. 2 Co 2,10-11. Le verset 11 est attesté sous cette forme par Ambroise, De paenitentia, I, 93, par l'Ambrosiaster, 2 Co, 2, 11 et par Pélage, 2 Co, 2, 11. Parmi les manuscrits bibliques, on trouve un texte pratiquement identique (non au lieu de nec) dans le Claromontanus, VL 75, et dans sa copie, VL 76, deux représentants de la forme $\mathbf{D}^{96}$. Le verset 10 , avec la leçon in facie là où la majorité des citations ont in persona, est cité ainsi dans VL 75 et 76, ainsi que dans le commentaire de Pélage.

42. 2 Co $12,20.21$. Paen agglutine le début du v. 20 et le v. 21 , ce qui explique sans doute la place particulière d'iterum. L'ajout d'ad uos après uenero est sans grande portée, et sa présence ponctuelle chez d'autres auteurs (Cyprien, Ep. 55, 26, 2; Chromace, Tractatus in Matthaeum, 17, 3, 4; Jérôme, In Isaiam, VII, 24) ne permet pas d'établir un lien significatif. Le verset est abrégé (il manque le premier complément immunditiam) et l'ordre particulier des mots est à rapprocher de Pélage, In 2 Co 12, 21 (éd. Souter): super quae gesserunt et fornicationem et inpudicitiam. Cette disposition suppose sans doute un déplacement de la proposition relative quam / quae gesserunt que l'on trouve attesté chez quelques auteurs: Cyprien, Ep. 55, 26, 2 (mais le vocabulaire est différent); Chromace, Tractatus in Matthaeum, 17, 3, 4 (et non egerunt paenitentiam in immunditia quam gesserunt, fornicatione et impudicitia; éd. Lemarié); Jérôme, Ep. 147, 1 (et non egerunt paenitentiam super immunditiam, quam gesserunt in inpudicitia et fornicatione; éd. Hilberg); et Pacien, Ep. 1, 5, 9 (et non egerunt paenitentiam ex his quae ante gesserunt in fornicatione et immunditiis suis?; éd. Granado).

40. 2 Co 7, 10. Les variantes de ce verset sont trop minces pour permettre de caractériser le texte de Paen. On notera simplement que Pélage, $2 \mathrm{Co}, 7,10$ a un texte parfaitement identique.

96. H.J. FREDE et R. GRYSON, Altlateinische Handschriften-Manuscrits vieux latins, p. 119 123 ; U. FRÖHLICH, Vetus Latina. Die Reste der altlateinischen Bibel, 22. Epistula ad Corinthios 1, Freiburg, 1995-, p. 195. 
43. 2 Co 13, 2. La petite vingtaine d'attestations présente un texte homogène. Le verset est presque identique au texte des fragments de Freising, VL 6497, un texte étroitement apparenté à celui qu'utilise Augustin, Contra epistulam Parmeniani, III, 3 (éd. Petschenig) : Praedixi et praedico sicut praesens secundo et nunc absens his qui peccauerunt et ceteris omnibus, quia si uenero iterum non parcam.

44. $2 \operatorname{Tm} 2,16-26$. La confrontation avec le matériel accumulé et classé par H.J. Frede ${ }^{98}$ montre que le texte cité dans Paen relève globalement du type $\mathbf{D}$, le texte attesté par Lucifer de Cagliari et Hilaire. On note des points de contact avec la Vulgate (v. 21 emundauarit; v. 24 mansuetum) et avec I, qu'atteste le texte de l'Ambrosiaster (pour le v. 17 par exemple).

Actes des apôtres

39. Ac 8, 20-23. Le texte des Actes est celui d'Ambroise et de Chromace d'Aquilée. Pour les v. 21-23, Paen est voisin d'Ambroise, De paenitentia, II, 23 (éd. Gryson): Non est tibi pars neque sors in hac fide, quia cor tuum non est rectum apud Deum. Paenitentiam itaque age ab hac nequitia tua et precare Deum, si forte remittatur tibi recordatio cordis tui; in obligatione enim iniquitatis et amaritudine fellis uideo te esse; mais cogitatio est le texte de la Vulgate. Pour le v. 20, le texte de Paen peut être rapproché de Chromace, Serm. 2,9 (éd. Lemarié): Tunc ait ad illum Petrus: pecunia, inquit, tua tecum sit in perditione, quia putasti te gratiam pecunia consequi posse; et d'Ambroise, Expositio Euangelii secundum Lucam, IX, 19 (éd. Adriaen): pecunia inquit tua tecum sit in interitum, quoniam gratiam dei putas te pecunia consequi posse; et De Nabuthae, 3, 13 (éd. Schenkl): pecunia tua tecum in perditionem.

Apocalypse

45. Ap 2, 5. Les conclusions que l'on peut tirer d'un seul verset sont nécessairement limitées. Paen a les caractéristiques de la version africaine ancienne $\mathbf{K}$ (memento, cecideris, leçon des manuscrits cisterciens que nous avons suivis plutôt que $P)^{99}$. La seconde partie du verset, pour laquelle la forme $\mathbf{K}$ n'est plus attestée, s'accorde avec Primase d'Hadrumète, Commentarius in Apocalypsin, I, 2. La transposition de mouebo à la fin du verset est spécifique à Paen.

97. H.J. FREDE et R. GRYSON, Altlateinische Handschriften-Manuscrits vieux latins, p. $98-100$.

98. H.J. FREDE, Vetus Latina. Die Reste der altlateinischen Bibel, 25. Epistulae ad Thessalonicenses, Timotheum, Titum, Philemoneum, Hebraeos, Freiburg, 1975-1991, p. 717-751.

99. R. GRYSON, Vetus Latina. Die Reste der altlateinischen Bibel, 26/2. Apocalypsis Johannis, Freiburg, 2000-2003. 


\section{Conclusion}

L'état de notre documentation rend parfois l'analyse du texte biblique délicate. Certains versets sont peu, voire pratiquement pas, attestés: en pareil cas, les données font défaut pour situer le texte. Par ailleurs, l'état médiocre de la tradition manuscrite de Paen doit inciter à la prudence. Il est difficile de mesurer les aléas de la transmission du texte biblique avant nos premiers témoins manuscrits et de préciser quelles ont pu être les interventions du compilateur sur le texte qu'il exploite. Cependant, lorsque la comparaison avec une autre source est possible, comme c'est le cas pour Ezéchiel et les Petits Prophètes avec VL 175 et VL 176, on constate qu'une forme ancienne du texte biblique a été fidèlement préservée.

Les rapprochements que l'on a pu opérer avec les manuscrits bibliques et les citations patristiques montrent que Paen reflète des formes du texte biblique attestées au $\mathrm{V}^{\mathrm{e}} \mathrm{s}$. Paen représente des états du texte biblique qui ne sont pas homogènes et que l'on peut résumer grossièrement ainsi : africain récent pour Ézéchiel, Isaïe et l'Apocalypse, proche du texte qu'utilisaient des auteurs italiens des $\mathrm{IV}^{\mathrm{e}}$ et $\mathrm{V}^{\mathrm{e}} \mathrm{s}$. pour les Petits Prophètes, Jérémie, les Actes des apôtres et les Épîtres pauliniennes. Par ailleurs, Paen présente des variantes isolées. Lorsque les attestations du verset sont peu nombreuses, il est difficile d'en tirer des conclusions. Mais dans d'autres cas, nous avons pu constater que les singularités de Paen pouvaient s'expliquer par une révision sur le grec (Is 31,$6 ; 43,26 ; 57,16 ; \mathrm{Jr} 2,32$ ) et par référence à la recension lucianique (Ez 18, 21 ; So 2, 1;2, 3; Is 57, 20; Jr 2, 25).

\section{B. Une localisation et une datation problématiques}

\section{1) Une fourchette chronologique large}

Wunderer tirait la datation et la localisation de Paen de l'analyse du texte biblique. Or il faut dissocier la datation de la source de Paen, le texte biblique, de la datation de Paen elle-même. Si les citations correspondent à des formes du texte biblique attestées au $\mathrm{V}^{\mathrm{e}} \mathrm{s}$., l'étude qui précède a aussi montré des utilisations plus tardives. À plusieurs reprises, nous avons rapproché le texte de Paen de celui que cite Gildas (milieu du $\mathrm{VI}^{\mathrm{e}} \mathrm{s}$.). La uetus translatio d'Is 30, 15 et de Mi 7, 2-3 est citée lors du huitième concile de Tolède (653). Le manuscrit de Saint-Gall (VL 176) enfin montre que des pans entiers d'une Bible vieille latine étaient encore disponibles au IX ${ }^{e} s$. De même, la présence d'un noyau «africain » est sans portée pour situer le lieu d'activité du compilateur. Les fragments de Constance, VL 175, qui comportent un texte africain pour Ézechiel mais européen pour les Petits Prophètes, viennent par exemple d'un manuscrit copié, selon les spécialistes, en Italie du Nord ${ }^{100}$. Les autres rapprochements plus ponctuels témoignent également de la circulation du texte biblique attesté dans Paen. Les coordonnées fournies par les répertoires - Afrique, $I V^{e}-V^{e}$ s. - doivent donc être revues. 
À s'en tenir aux données examinées jusqu'à présent, on aboutit à une fourchette chronologique très large: entre le $\mathrm{V}^{\mathrm{e}} \mathrm{s}$., date à laquelle la source biblique est bien attestée, et le XII $\mathrm{s}$., époque des premiers témoins manuscrits.

\section{2) La question du contexte intellectuel}

Est-il possible de restreindre cette fourchette chronologique en précisant dans quel contexte a été réuni le dossier biblique de Paen?

Les manuscrits les plus anciens nous apprennent peu de choses. Paen fait partie d'une collection qui rassemble des textes patristiques antiques sur le thème de la pénitence et de la confession. Cette collection était visiblement destinée à un usage monastique. Les cisterciens ont-ils repris tel quel un texte antique? La structure de Paen - constituée d'un unique dossier - ne semble pas compatible avec une telle hypothèse. Paen apparait plutôt comme une partie d'un texte - par exemple une section d'un florilège thématique. Il pourrait aussi s'agir d'une annexe à un autre texte, qui prendrait la forme d'un dossier biblique dont le titre sommaire donnerait la direction générale. Les florilèges étaient une forme prisée par les cisterciens, mais l'utilisation massive de citations non conformes au texte biblique reçu semble s'opposer à ce que Paen ait été composé par les cisterciens. Le cas d'Isaïe est significatif. L'éditeur de la Vetus Latina d'Isaie, R. Gryson, insiste sur le succès précoce de la traduction de Jérôme et sur le caractère marginal de la survivance des anciennes versions d'Isaïe ${ }^{101}$. Or Paen peut être défini comme un bloc de citations «vieilles latines», ce qui trahit un emprunt à un autre texte.

La structure de Paen ainsi que la nature de son texte biblique impliquent l'exploitation d'une source reprise par les cisterciens pour être intégrée à une collection thématique. Il est naturellement difficile de préciser la nature des aménagements qui ont pu être apportés à cette source lorsqu'elle a été récupérée pour figurer dans une série de textes sur la pénitence.

Le choix des citations n'est pas d'un grand secours pour définir dans quelle intention elles furent réunies. Les trois éditeurs du texte, Trombelli, Wunderer et Miodoński, pensaient que Paen avait été compilé pour lutter contre les Novatiens ${ }^{102}$. Trombelli, qui tenait le texte pour authentique, y voyait un florilège dirigé contre Novatien lui-même, tandis que Wunderer et, à sa suite, Miodoński aménageaient la thèse de Trombelli à une datation plus basse: Paen serait un témoignage, avec les écrits de Pacien et d'Ambroise, sur les développements ultérieurs de la polémique. Wunderer s'appuyait principalement sur le spectre

101. R. GRYSON, Vetus Latina. Die Reste der Altlateinischen Bibel, 12. Esaias, p. 1649-1650. VL 176 en est une illustration: Isaie y est copié selon la Vulgate, alors qu'Ézéchiel et les Petits Prophètes sont «vieux latins». Gildas cite aussi un texte vieux latin pour Ezéchiel et les Petits Prophètes, mais vulgate pour les autres livres.

102. H.J. VOGT ne souscrivait sans doute pas à cette interprétation puisque Paen n'est pas cité dans sa synthèse sur Novatien et les Novatiens, Coetus Sanctorum. Der Kirchenbegriff des Novatian und die Geschichte seiner Sonderkirche, Bonn, 1968. 
des citations bibliques: bien que le texte biblique des deux auteurs soit différent, on retrouverait dans Paen les citations retenues par Pacien de Barcelone ${ }^{103}$. Une comparaison plus large, entre Paen et un corpus de textes écrits contre Novatien ${ }^{104}$, montre que cette hypothèse n'est pas convaincante. En dépit de coïncidences frappantes $^{105}$, les citations alléguées dans l'un et l'autre cas ne sont pas identiques. Il est délicat de raisonner sur des absences ( $(12,12-13$ par exemple, les évangiles), qui peuvent résulter d'un aléa de transmission ou d'un abrègement du texte. On sera plus sensible à la présence de textes qui sont rarement cités dans le cadre de la controverse contre les Novatiens (Jérémie, les Lamentations, l'Ecclésiastique ${ }^{106}$ ) et d'un texte, Ac 8, 20-23, qui était précisément allégué par les Novatiens ${ }^{107}$. La rubrique du florilège, qui en constitue l'exégèse, n'oriente pas non plus dans ce sens. On rencontre certes des formules analogues sous la plume des adversaires des Novatiens à propos de la rémission des péchés ${ }^{108}$, mais la rubrique de Paen reste très vague, et elle ne fait pas écho à ce qui est précisément au cœur de la polémique, entre autres la possibilité pour l'Église de remettre les péchés les plus graves.

De manière significative, la proportion de citations communes est tout aussi grande lorsqu'on compare Paen à d'autres textes sur la pénitence. La section $D e$ paenitentia du Speculum pseudo-augustinien par exemple a onze extraits communs avec Paen, auxquels on peut ajouter cinq citations en partie communes (Paen citant des extraits plus étendus); la lettre 122 de Jérôme, Ad Rusticum de paenitentia, présente aussi un nombre non négligeable de citations communes avec Paen, en particulier des citations de Jérémie: onze extraits (dont quatre sont plus courts chez Jérôme).

Ainsi, tant en ce qui concerne le choix des citations que leur exégèse, on ne retrouve pas d'éléments contraignants pour voir dans Paen un florilège compilé par un adversaire de Novatien. On peut penser que l'attribution à Cyprien a influencé les éditeurs du texte et les a amenés à surévaluer des coïncidences dans

103. C. WUNDERER, éd. cit., p. 30-34.

104. On en trouvera une liste dans l'ouvrage de H.J. Vogt. Ont été pris en compte les écrits de Cyprien, l'Ad Nouatianum pseudo-cyprianique, la question 102 de l'Ambrosiaster, le De paenitentia d'Ambroise et les écrits de Pacien de Barcelone.

105. Voir par exemple PS.-.CYPRIEN, Ad Nouatianum, 10, qui cite un petit dossier vétéro-testamentaire où l'on retrouve Ps 88, 31-34; Ez 33, 10-11; Is 57, 16;57, 17; 57, 18.

106. Jr 8, 4 est cité par PACIEN, Sermo de paenitentibus, 12, 4 et Ep. 1, 5, 7; Lm 3, 31-33 par AMBRoISE, De paenitentia, I, 5, 23.

107. La réponse de Pierre à Simon le Magicien fait l'objet d'une analyse approfondie chez Ambroise, De paenitentia, II, 5, 29-35. Cf. aussi AmbrosIASTER, Questiones Veteris et Noui Testamenti, 102, 24.

108. AMBrosIASTER, Questiones Veteris et Noui Testamenti, 102, 12 (éd. Souter): siue iam credentibus per paenitentiam siue futuris credentibus per baptismum omnia remittentur peccata. 
les constellations de citations bibliques, alors qu'elles ne sont pas plus importantes qu'avec d'autres écrits sur la pénitence, quel que soit le genre considéré (florilège ou écrit parénétique).

Le choix des citations ne permet pas de rattacher Paen à un débat particulier sur la pénitence. Les citations sont choisies pour exhorter à la conversion du cour et un petit nombre d'entre elles parce qu'elles énoncent des menaces à l'égard des pécheurs endurcis. La présence de conuerto (ou d'un mot apparenté) et/ou de paenitentia, deux mots clefs de la rubrique introductive, semble être un critère déterminant pour le choix des citations. La constellation de citations ne permet pas non plus de rattacher Paen a un autre texte, florilège scripturaire ou écrit sur la pénitence, qui aurait servi de source. Même si on laisse de côté la question du texte biblique cité, on ne retrouve jamais le même choix de citations bibliques, que ce soit dans le domaine grec ou dans le domaine latin. Certaines citations sont classiques sur le thème de la conversion, Ez 33, 11 ( $\left.\mathrm{n}^{\circ} 27\right)$ ou 18, $21-23\left(\mathrm{n}^{\circ} 29\right)$ par exemple. Mais le compilateur a également sélectionné des textes qui sont assez peu allégués, ou qui apparaissent surtout dans des commentaires exégétiques suivis, tels Jr 2, 25; Is 54, 7-8; Ez 17, 24; Ez 36, 36; Si 20, 4109; 2 Co 13, 2. Notre recherche d'une source ou d'une tradition indirecte est donc restée vaine.

Peut-on tirer parti de l'ordre des citations? On est handicapé par le caractère sélectif du florilège. Certains livres bibliques ne sont pas cités, les évangiles par exemple; parmi les écrits que la tradition latine a considérés comme les Écrits de Salomon, seul l'Ecclésiastique est représenté ; il n'est donc pas possible de savoir si, dans la Bible que reflète Paen, l'Ecclésiastique se lisait dans un tel ensemble, et à quelle place précisément ${ }^{110}$. Le fait que certains livres ne soient représentés que par un unique verset est une difficulté supplémentaire. Le déplacement d'un verset de Jérémie au milieu de l'ensemble Isaïe $\left(n^{\circ} 4\right)$ et les entorses à l'intérieur d'un livre dans l'ordre des versets incitent à ne considérer comme significatifs que les grands ensembles de citations. Compte tenu de ces remarques, le fait qu'Osée ne soit pas cité en première position, comme c'est l'habitude dans la Bible grecque et dans la Bible hébraïque, ne doit sans doute pas être surévaluél11. Pour la même raison (un seul extrait cité), on peut se demander si la place des

109. La base de données Biblindex ne recense qu'une seule citation patristique d'Ez 36, 36 (au 11 avril 2009); le fichier numérisé du Vetus Latina Institut de Beuron comporte sept attestations. Pour Si 20, 4, W. THIELE, Vetus Latina. Die Reste der altlateinischen Bibel, 11/2. Sirach, Ecclesiasticus, ne donne qu'une citation patristique en plus de Paen, Defensor de Ligugé, Liber scintillarum, 9, 4 (sur la pénitence).

110. Voir la typologie dressée par W. THIELE, Vetus Latina. Die Reste de altlateinischen Bibel, 11/1. Sapientia, Freiburg, 1977-1985, p. 222-232.

111. Pour une étude de l'ordre des Petits Prophètes, on se reportera à l'introduction de T. Muraoka, La Bible d'Alexandrie, 23. 1, p. I-VI. 
Psaumes est significative. En revanche, il est sûrement significatif que les Petits Prophètes suivent les Grands Prophètes, c'est-à-dire que 1'ordre adopté ne soit plus celui de la Bible grecque ${ }^{112}$.

Si l'on tient compte de ce dernier élément et si l'on s'appuie sur les témoignages patristiques les plus tardifs en ce qui concerne le texte biblique cité, on peut émettre l'hypothèse que Paen dérive d'une source remontant au VI ${ }^{\mathrm{e}}$ ou au vIre siècle, et qui aurait été exploitée en milieu cistercien, sans doute par l'intermédiaire d'un exemplaire carolingien. La réputation de Cyprien comme auteur de florilèges bibliques, l'importance du thème de pénitence dans ses écrits suffisent à expliquer que le nom de l'évêque de Carthage se soit imposé pour pallier l'anonymat du texte 113 .

\section{IV. - CONCLUSION}

L'étude de l'histoire du texte modifie quelque peu l'image que l'on avait de Paen. Paen est un bloc erratique de citations bibliques, mis en circulation par des manuscrits cisterciens. Le texte biblique est «vieux latin», avec des affinités nettes pour la partie Ézéchiel - Petits Prophètes avec les manuscrits bibliques VL 175 et 176.

L'attribution à Cyprien a assuré une certaine diffusion au florilège et il est assez facile de «descendre » l'histoire du texte. En l'état actuel de notre documentation, il n'est en revanche pas possible de reconstituer l'histoire de Paen avant sa mise en circulation par les cisterciens. La structure du texte, ainsi que la présence d'un texte biblique non conforme à la Vulgate - en particulier pour les prophètes où l'écart avec la traduction de Jérôme sur l'hébreu est important - permettent de supposer que les cisterciens ont repris une source - section de florilège, dossier biblique annexé à un autre texte -, qui réunissait déjà ces citations.

La date et la localisation proposées par les répertoires ne peuvent être maintenues. Le texte biblique date du $V^{e} s$. et il est sporadiquement attesté jusqu'au VII ${ }^{e} s$, On peut donc avancer que les cisterciens ont dû exploiter un dossier constitué au $\mathrm{VI}^{\mathrm{e}}$ ou au VII ${ }^{\mathrm{e}} \mathrm{s}$, dans des circonstances qu'il resterait à préciser. Rien ne permet en tout cas d'affirmer que Paen ait été compilé pour lutter contre les Novatiens.

112. À l'exception du Sinaïticus. Rufin, Expositio Symboli, 35, adopte également l'ordre Grands Prophètes - Petits Prophètes. L'ordre dans lequel Rufin énumère les livres bibliques présente des points communs avec celui de Paen: la seule différence concerne le livre des Psaumes, cité après le livre des Douze Prophètes et Job. Voir M. STENZEL, «Der Bibelkanon des Rufin von Aquileja», Biblica, 23, 1942, p. 43-61: Rufin représente un intermédiaire entre la Bible grecque qu'atteste aussi la tradition latine (les Petits Prophètes sont énumérés avant les Grands Prophètes) et l'ordre de la Bible hébraïque sur ce point, qu'on retrouvera dans la Vulgate.

113. Les versets cités du psaume 88 , ainsi que Ap 2,5, c'est-à-dire les extraits qui ouvrent et ferment le florilège, sont d'ailleurs souvent cités par Cyprien dans ses écrits sur la pénitence des lapsi. Cf. Ep. $11,2,1 ; 55,22,2 ;$ De lapsis, 6 pour le psaume $88 ; E p .19,1 ; 34,1 ; 55,22,1 ; D e$ lapsis, 16 pour Ap 2, 5. 
L'intérêt principal de Paen réside dans son texte biblique. On y trouve des versets rarement - voire pratiquement jamais - cités. Son texte présente parfois des leçons singulières, illustrant ainsi cette variété de la Bible latine que déplorait Augustin. Seuls des spécialistes de la Bible latine pourront pleinement évaluer son témoignage pour les livres qui n'ont pas encore été publiés par le Vetus Latina Institut de Beuron, mais il semble d'ores et déjà qu'il faille réviser les conclusions de Wunderer à propos du texte biblique de Paen: Paen reflète un état du texte attesté au $V^{e}$ s., mais ce n'est pas un texte homogène. On ajoutera que la section Ézéchiel - Petits Prophètes serait sans doute à mettre à contribution à propos de l'étude des rapports entre VL 175 et 176.

Pour ces raisons, il nous a semblé intéressant de proposer une nouvelle édition de Paen, plus accessible et qui tienne compte des témoins les plus anciens.

\section{V. - ÉDITION DU TEXTE}

\section{A. Principes d'édition}

Notre édition de Paen est fondée sur six manuscrits: les trois témoins les plus anciens, $G, H$ et $P$, ainsi que trois recentiores: $M, B$ et $A$.

Les manuscrits $G$ et $H$, que ne connaissaient pas les éditeurs précédents, offrent le meilleur texte et permettent de renforcer le témoignage de $P$, là où Miodoński l'avait jugé fautif ou incertain. En pratique, nous éditons le texte des manuscrits cisterciens, à l'exception de quelques passages où il apparaît que leur source était fautive. En revanche, lorsqu'il nous a semblé que le texte correspondait à une particularité du texte biblique, nous n'avons pas corrigé. En cas de désaccord entre $G$ et $H$ d'une part, $P$ d'autre part, nous avons suivi les manuscrits cisterciens.

L'histoire du texte a montré que les recentiores n'apportaient rien pour l'établissement du texte. Il nous a toutefois paru important que les variantes de cette famille figurent également dans l'apparat critique, comme témoignage sur l'histoire du texte (sa dégradation dans les manuscrits récents) et sur la tradition imprimée, exclusivement (dans le cas de Trombelli et Wunderer) ou partiellement (l'édition de Miodoński) dépendante de cette famille. Faire figurer tous les recentiores aurait inutilement alourdi l'apparat critique, car la famille est très homogène. Nous avons donc retenu les manuscrits utilisés par nos prédécesseurs: $B$, le manuscrit de Bologne, source de l'édition de Trombelli, ainsi que $M$ et $A$ utilisés par Wunderer et Miodoński. La présence de $M$ s'imposait pour une autre raison: $M$ conserve un certain nombre de bonnes leçons là où les autres manuscrits tardifs ont un texte corrompu.

Aux témoins manuscrits s'ajoutent les trois éditions imprimées. L'apparat critique est négatif. Il devient ponctuellement positif lorsque la leçon des manuscrits les plus anciens avait été conjecturée par les éditeurs du XIX ${ }^{\mathrm{e}} \mathrm{s}$. Les variantes orthographiques n'ont pas été prises en compte. 


\section{B. Conspectus siglorum}

Les manuscrits

$G \quad$ København, Det Kongelige Bibliotek, Ny. Kgl. S. $2740,4^{\circ}, 3^{\mathrm{e}}$ quart du XII s., f. $5 v-10 \mathrm{r}$

$H \quad$ Paris, BnF, lat. 18072, ca $1155-1165$, f. $21 \mathrm{v}-26 \mathrm{r}$

$P \quad$ Paris, Bibl. de l'Arsenal 550, XIII' ${ }^{\mathrm{e}}$ s., f. 128va-130ra

$M \quad$ Madrid, Bib1. Nac. 5569, XV s. [1416], f. 149rb-151va

$B \quad$ Bologna, Bibl. Univ. 2364, XVe s., f. 170r-172r

A Augsburg, Staats- und Stadtsbibliothek, Fol. Cod. 65, milieu du XV $\mathrm{XV}^{\mathrm{e}} \mathrm{s}$, f. $216 \mathrm{v}-219 \mathrm{r}$

Les éditions

Tr édition Trombelli: Veterum Patrum Latinorum opuscula nunquam antehac edita. Anecdotorum a Canonicis Regularibus S. Salvatoris evulgatorum. Tom. II, pars I, Bononiae : apud Hieronymum Corciolani, 1751, p. 3-6

Wu édition Wunderer: Bruchstücke einer afrikanischen Bibelïbersetzung in der pseudocyprianischen Schrift Exhortatio de paenitentia, Erlangen, 1889

Mi édition Miodoński: A. Miodoński, «Incerti auctoris Exhortatio de paenitentia», Rozprawy Akademii Umiejętności. Wydziat Filologiczny, 2, 5, Krakau, 1894, p. 125-134

Abréviations

ac

ante correctionem

coni. coniecit

in app.

in apparatu critico

ind.

lac.

indicauit

$\mathrm{mg}$

om.

lacuna

in margine

pc

omisit

ras

post correctionem

secl.

in rasura

sl

seclusit

supra lineam 


\section{Exhortatio de paenitentia}

Per paenitentiam posse omnia peccata dimitti ei qui ad Deum toto corde conuersus sit.

1. In psalmo octogesimo octauo (Ps 88, 31-34): Si dereliquerint filii eius legem meam et in iudiciis meis non ambulauerint et mandata mea non custodierint, uisitabo in uirga iniquitates eorum et in uerberibus peccata eorum. Misericordiam autem meam non dispergam ab eis.

2. Item apud Isayam (Is 30,15): Sic dicit Dominus sanctus Israel: cum conuersus ingemueris, tunc saluus eris et scies ubi fueris.

3. Item illic (Is 30, 1): Vae, filii desertionis, dicit Dominus, fecistis consilium non per me et sponsionem non per spiritum meum, adicere peccatum super peccatum.

4. Item apud Theremiam (Jr 2,25): Auerte pedem tuum ab aspera uia et faucem tuam a siti. Illa uero dixit : confortabor, nolo; quia diligebat alienos et ibat post illos.

5. Item apud Isayam (Is 31,6$)$ : Conuertimini, qui altam cogitationem cogitatis et iniquam.

6. Item illic (Is 43, 25-26): Ego sum, ego sum qui deleo iniustitias tuas, et non recordabor. Tu autem recordare, et iudicemur simul; dic tu iniustitias tuas prius ut iustificeris.

7. Item illic (Is 55, 6-7): Quaerite Deum et cum inueneritis eum inuocate. At ubi appropinquauerit uobis, derelinquat impius uias suas et uir iniquus cogitationes suas et conuertatur ad Dominum, et misericordia ei praestabitur, quia in multum remittit peccata uestra.

exhortatio beati cypriani de paenitentia $G H$ exhortatio sancti cipriani de paenitentia $P$ incipit exhortatio beati cypriani de paenitentia $M$ exhortatio sancti (sancto $A^{\mathrm{ac}}$ ) cypriani de paenitentia incipit $A B$ exhortatio s. cypriani de poenitentia incipit $T r$ exhortatio ad poenitentiam coni. in app. Tr

1. octogesimo : octuagesimo $A B \operatorname{Tr} W u \|$ dereliquerint : derelinquerint $P A B M i \|$ eorum ${ }^{2}$ om. $P$

2. sic : sicut $A B \operatorname{Tr} W u M i \|$ dominus : deus $P \|$ cum : quoniam $A^{\text {ac }}$

3. desertionis : disertionis $G^{\text {ac }} A B \|$ dominus : deus $P \|$ fecistis : fecisti $P \|$ consilium : concilium $A$ ll sponsionem: s. meam $A B \operatorname{Tr} \|$ adicere : abicere $A^{\text {ac }}$

4. auerte GHP $M$ coni. in app. $\operatorname{Tr} W u M i$ : auertere $A B \operatorname{Tr} \|$ faucem coni. Wu Mi : faciem codd. $\operatorname{Tr}$ \| confortabor : confortari coni. Mi $\|$ nolo : uolo $M A B$ Tr Wu Mi

5. qui GHP $M$ coni. in app. Tr Wu $M i$ : quia $A B$ Tr

6. ego sum om. $A W u \|$ deleo : doleo $A B \| \mathrm{et}^{2}$ : ut $P \|$ ut iustificeris om. $M A B \operatorname{Tr} W u$

7. deum : dominum $P M i$ ll appropinquauerit : appropinquerit $M$ appropinquarunt $A$ appropinquauit $B \operatorname{Tr} \|$ derelinquat : delinquat $A \|$ suas $^{1}$ om. $M \|$ ei : eius $P \|$ praestabitur : praeparabitur $B T r \|$ in multum : non in multum $M$ non multum $A B T r$ 
8. Item illic (Is 44, 21-22): Recordare haec, Iacob et Israel, quia puer meus es. Vocaui te puerum meum, et tu, Israel, noli obliuisci mei. Ecce enim abstersi sicut nubem iniustitias tuas et sicut nimbum peccata tua. Conuertere ad me, et redimam te.

9. Item illic (Is 46, 8-9): In mente habete haec et gemite; paenitemini, qui seducti estis, conuertimini corde ad me. Et in mente habete priora saecula, quia ego Deus.

10. Item illic (Is 54, 7-8): Tempore pusillo dereliqui te et cum misericordia magna miserebor tui. In furore pusillo auerti faciem meam abs te et in misericordia aeterna miserebor tui.

11. Item illic (Is 57, 15-21): Haec dicit excelsus in excelsis habitans in aeternum, sanctus in sanctis, nomen est ei, Dominus excelsus in sanctis requiescens et pusillanimis dans animi aequitatem et dans uitam contribulatis corde. Non in sempiternum irascar uobis nec per omnia uindicabo in uos; spiritus enim a me prodiet, et inspirationem omnem ego feci. Et propter peccatum pusillum quid contristaui eum et auerti faciem meam ab eo, et bilem passus est et abiit tristis in uiis suis. Vias eius uidi et sanaui eum et consolatus sum eum et dedi ei consolationem ueram, pacem super pacem his qui longe et his qui prope. Et dixit Dominus: sanaui eos. Iniqui autem, ut mare commotum, sic fluctuabuntur et quiescere non possunt. Non est gaudere impiis, dicit Dominus.

12. Item apud Iheremiam (Jr 2, 32): Numquid obliuiscetur sponsa ornamenti sui aut uirgo fasciae pectoralis suae? Populus uero meus oblitus est mei dierum, quorum non est numerus.

13. Item illic (Jr 18, 7-10): In summa loquar super gentem aut super regnum ut auferam eos et perdam; et si conuersa fuerit gens illa a malis suis, paenitebo de malis, quae cogitaui facere illis. Et in summa loquar super gentem et regnum ut reaedificem et plantem; et facient mala ante me ut ne audiant uocem meam, et paenitebo de bonis, quae locutus sum facere eis.

8. nubem: om. $A B \quad$ lac. ind. $\operatorname{Tr} \|$ tuas : meas tuas $M \|$ nimbum : imbrem $A B \operatorname{Tr} W u \| \mathrm{te}^{2}$ : ad te $A^{\text {ac }}$

9. estis : estis et $M A B \operatorname{Tr} W u \|$ corde $A^{\text {st }}$

10. te om. $^{1} B \operatorname{Tr} \|$ in furore - tui om. $A \|$ auerti : auerte $M \| \mathrm{et}^{2}$ om. $M B \operatorname{Tr} W u \|$ miserebor : miserabor coni. in app. $M i$

11. dicit : dixit $A B \operatorname{Tr} W u \|$ excelsus : dominus e. $P$ excelsis $A B \|$ irascar : irascor $A B \operatorname{Tr} \|$ uindicabo : uindicabor $H^{\text {ac }} P \|$ quid om. MAB Tr Wu ll bilem coni. Wu Mi : uilem codd. Tr Il suis om. $M A B \operatorname{Tr} W u \|$ eius : enim $A B \|$ sum eum : sum ego $M A B \operatorname{Tr} W u \|$ ei om. $P \|$ pacem : et pacem $M A B$ $\operatorname{Tr} W u M i \|$ super - longe et om. $A \|$ his ${ }^{1}:$ hiis $W u$ iis $\operatorname{Tr} \|$ his $^{2}:$ hiis $M A B W u$ iis $\operatorname{Tr}$

12. sui om. $A$ \|l pectoralis : temporalis $A^{\text {ac }} \|$ uero $P^{\text {sl }} \|$ dierum : diebus coni. in app. $T r$

13. ut auferam GHP coni. Wu $M i$ : ant a. $M A B \operatorname{Tr} \|$ perdam : p. perdam $B^{\text {ac }} \|$ illa $o m$. $M A B \operatorname{Tr} W u \|$ quae coni. in app. $\operatorname{Tr} W_{u} M i$ : quod codd. $\operatorname{Tr} \|$ cogitaui : cogitare $M \|$ illis : in illis $H^{\text {ac }} \|$ in summa GHP coni. Wu $M i$ : summa $M A B \operatorname{Tr} \|$ et regnum : aut r. $A B \operatorname{Tr} W u \|$ ne audiant : ne audient $M$ non audient $A B$ non audiant $T r$ 
14. Item illic (Jr 3, 12): Reuertere ad me, habitatio Israel, dicit Dominus, et non firmabo faciem meam super uos, quia misericors ego sum, dicit Dominus, et non irascar uobis in aeternum.

15. Item illic (Jr 3, 14-15): Conuertimini, filii qui recessistis, dicit Dominus, quoniam ego dominabor uestri et accipiam uos unum de ciuitate et duos de familia et inducam uos in Syon et dabo uobis pastores secundum cor meum, et pascent uos pascentes cum disciplina.

16. Item illic (Jr 3, 22): Conuertimini, filii conuertentes, et ego sanabo contritionem uestram.

17. Item illic (Jr 4, 14): Ablue a malitia cor tuum, Ierusalem, ut salueris. Vsquequo erunt in te cogitationes dolorum tuorum?

18. Item illic ( $\mathrm{Jr} 8,4-5):$ Haec dicit Dominus: numquid qui cadit non resurgit? aut qui auertit se non conuertetur? Quia auertit se populus iste auersione improba et obtinuerunt praesumptione sua et noluerunt conuerti?

19. Item illic (Jr 8,6): Non est homo paenitentiam agens a malitia sua, dicens: quid feci? Defecit qui currit cursu suo, sicut equus sudans in hinnitu suo.

20. Item illic (Jr 18, 11-12): Auertatur ergo unusquisque a uia sua mala, et meliora facite studia uestra. Et dixerunt : confortabimur, quia post adinuentiones nostras ibimus, et unusquisque quae placent cordi suo mala faciemus.

21. Item illic (Lm 2, 18) : Effunde sicut currens fluuius lacrimas die ac nocte; noli dare tibi requiescere; non sileat pupilla oculi tui.

22. Item illic (Lm 3, 40-42): Perscrutemur uias nostras et conuertamur ad Dominum; mundemus corda cum manibus nostris et respiciamus ad Deum, qui habitat in caelis. Nos peccauimus et irritauimus, et tu non es propitiatus.

15. dicit dominus : dominus dicit $B^{\text {ac }} \|$ familia : familias $A \|$ inducam : ducam $A \|$ dabo : dabor $A^{\text {ac }}$ II pastores : pastorem $A^{\text {ac }} \|$ meum : me $M^{\text {ac }}$

16. contritionem : contributionem $A$ contribulationem $W u$

17. ablue : adhuc $A$ Il salueris : saneris $M A B \operatorname{Tr} W u$

18. dicit : dic $A$ \|l qui cadit $P^{s 1} \|$ auersione : a prouisione $A^{a c}$ a uisione $A^{\mathrm{pc}} B \operatorname{Tr} \|$ improba : in improba $A^{\text {ac }}$

19. a : om. $A$ ac $B^{\text {ac }} \|$ sudans $G H P$ coni. Wu $M i$ : suadens $M A B$ Tr

20. adinuentiones: aduentiones $P^{\mathrm{ac}} \|$ nostras $G H P M$ coni. in app. $\operatorname{Tr} W u M i$ : uestras $A B \operatorname{Tr} \|$ mala : malo coni. in app. Wu

21. effunde: effundens $A^{\text {ac }} \|$ currens fluuius : currens $A B$ Wh $M i$ torrens $\operatorname{Tr} \|$ requiescere: requiem $P M^{\mathrm{pc}} A B$ Tr

22. deum : dominum $A B \operatorname{Tr} W u M i l l$ qui habitat : q. h. qui habitat $A$ II propitiatus : propiatus $A$ 
23. Item illic (Jr 3, 6-7): Et dixit Dominus ad me in diebus regis Iosiae: uidisti quae fecit mihi habitatio domus Israel? Abiit super omnem montem excelsum et subiit usque ad omne lignum nemorosum et fornicata est illic. Et dixi postquam fornicata est haec omnia: ad me conuertere, et non est reuersa.

24. Item illic (Lm 3, 31-33): Non repellet in aeternum Dominus, quia, cum humiliauerit, miserebitur secundum multitudinem misericordiae suae, quia non humiliabit ex toto corde suo neque repellet filios hominum.

25. Item apud Iezechielem (Ez 33, 12-16): Et iustus non poterit saluus esse in die peccati. Cum iusto dicam: uita uiues, ipse uero confidet super iustitiam suam et fecerit iniquitatem, omnes iustitiae eius non commemorabuntur; in sua iniquitate quam fecit, in ea morietur. Et cum dicam impio: morte morieris, et auerterit se a peccato suo et fecerit iudicium et iustitiam et pignus debitori reddiderit et rapinam restituerit, in praeceptis uitae ambulauerit, ne faciat iniquum, uita uiuet et non morietur; omnia peccata eius, quae peccauit, non commemorabuntur ei; quia iudicium et iustitiam fecit, in ipsis uiuet.

26. Item illic (Ez 17, 24): Ego Dominus, qui humilio lignum altum et exalto lignum humile, et arefacio lignum uiride et reuiuiscere facio lignum aridum.

27. Item illic (Ez 33, 10-11): Et tu, fili hominis, dic domui Israel: sic locuti estis dicentes: errores nostri et iniquitates nostrae in nobis sunt, et in ipsis nos tabescimus, et quomodo uiuemus? dic illis : uiuo ego, dicit Dominus, si uolo mortem impii; tantum a uia sua conuertatur, et uiuat.

28. Item illic (Ez 36, 36): Ego Dominus aedificaui demolita et plantaui exterminata.

23. dominus : deus $P \|$ regis iosiae : iosiae regis $M T r W u M i$ iosue regis $A B \|$ mihi : mi Wu $M i \|$ domus delendum esse coni. $\operatorname{Tr} W u$ Mi ll usque om. $A B \operatorname{Tr} W u \|$ nemorosum : memorosum $M$

24. quia' : et $M A B \operatorname{Tr} W u \|$ repellet $^{2}$ : expellet $A W u$

25. apud iezechielem: i. apud $H^{\text {ac }} \|$ confidet: si confidet coni. in app. Tr $\|$ commemorabuntur $^{1}$ : commobuntur $M^{\text {ac }} \quad$ commonebuntur $M^{\text {cc }} \|$ fecit ${ }^{1}$ : fecerit $M A B$ Tr Wu Mi ll morte om. A \| auerterit : auertit $M A B \operatorname{Tr} W u M i \|$ iudicium et iustitiam ${ }^{1}$ : iustitiam et iudicium $M A B \operatorname{Tr} W u \|$ debitori : redditori d. $A B^{\text {ac }} \|$ peccauit : fecit $H \|$ commemorabuntur ${ }^{2}$ : commouebuntur $M A B \operatorname{Tr}$ commonebuntur coni. Wu

26. qui : quia $A B \operatorname{Tr} \|$ lignum $^{\mathrm{l}} P^{\text {sl }}$

27. domui : habitationi coni. in app. Wu ll israel : istis $A \|$ sic : sicut $\operatorname{Tr} \|$ in ipsis : ipsis $A \|$ uiuemus om. $A \| \operatorname{dic}^{2}$ : dicit $M A B \|$ dominus : deus $P \|$ si delendum esse coni. in app. $M i \|$ uolo : nolo $W u$ $M i \|$ conuertatur : auertatur $A B \operatorname{Tr} W u \|$ uiuat : uiuet $\operatorname{Tr}$

28. dominus : deus $P \|$ exterminata : et e. $A^{\text {ac }}$ 
29. Item illic (Ez 18, 21-23): Et iniquus si conuertat se ab omnibus iniquitatibus, quas fecit, et custodiat omnia mandata mea et faciat iudicium et iustitiam et misericordiam, uita uiuet et non morietur. Omnia delicta eius, quaecumque fecit, non erunt in memoria; in sua iustitia quam fecit uiuet. Numquid uoluntate uolo mortem iniusti, dicit Adonay Dominus, quam ut auertat se a uia sua mala et uiuere eum?

30. Item illic (Ez 18, 30-32): Conuertimini et auertite uos ab omnibus impietatibus uestris, et non erunt uobis in poenam iniquitates. Proicite a uobis omnes iniquitates uestras, quas impie fecistis in me, et facite uobis cor nouum et spiritum nouum. Et ut quid moriemini, domus Israel? Quia nolo mortem morientis, dicit Adonay Dominus.

31. Item apud Danielem (Dn 4, 34-35 LXX): Et post finem dierum, ego Nabuchodonosor, oculos meos in caelum sustuli, et sensus meus in me conuersus est, et altissimum laudaui et regem caeli benedixi et uiuentem in saecula laudaui, quoniam potestas eius aeterna est, regnum eius in generationem et generationem, et omnes qui inhabitant terram nihil existimati sunt.

32. Item apud Micheam (Mi 7, 1.2-3): Heu mihi! anima mea, quia periit reuerens a terra, et qui corrigat inter homines non est! Omnes in sanguine iudicantur, unusquisque proximum suum tribulat tribulatione. In malum manus suas praeparant.

33. Item illic (Mi 7, 8-9): Noli gaudere super me, inimica mea, quia cecidi; sed resurgam, propter quod si sedero in tenebris, Dominus lucebit mihi. Iram Domini sustinebo, quia peccaui ei, donec iustificet ipse causam meam.

34. Item apud Sophoniam (So 2, 1-3): Conuenite et precamini, gens indisciplinata, priusquam efficiamini sicut flos praeteriens, priusquam ueniat super uos ira Domini, priusquam ueniat super uos dies furoris Domini. Quaerite Dominum, omnes humiles terrae, iudicium operamini et quaerite iustitiam; quaerite mansuetudinem et respondete ea, ut protegamini in die irae Domini.

29. omnibus : homnibus $M^{a} \|$ iudicium et secl. $M i \|$ quaecumque : quae $A B \operatorname{Tr} W u \|$ uolo : nolo $A B \|$ iniusti : iniqui $W u M i$

30. iniquitates ${ }^{1}$ : om. $T r$ iniquitatis coni. Mi $\|$ et facite : facite $A \| l$ mortem morientis : m. mortem $A^{\text {ac }}$

31. nabuchodonosor: nabugodonosor $M \|$ quoniam : qui $M$ quia $A B \operatorname{Tr} W u \|$ generationem et generationem : generatione et g. $M W u$ generatione $A B T r \|$ existimati sunt : aestimati sunt $p^{a c}$ om. MAB Tr $W_{u}$

32. mihi : mi $W u M i \|$ reuerens : reuerans $H^{\text {ac }}$ uerens $M^{\text {ac }}$ non legitur $M^{\text {pc }} \quad$ ueritas $A B \operatorname{Tr} W_{u}$ $\|$ homines : omnes $A B \operatorname{Tr} \|$ iudicantur coni. Wu Mi : iudicant codd. Tr indicant coni. in app. Mi \| suum om. $M A B \operatorname{Tr} W u$ \|l tribulat : tribuat $A B \|$ in malum : malum $A$

33. resurgam : resurgat $A^{\text {ac }} \|$ domini : domino $M A B \operatorname{Tr} \|$ ei : et $A$

34. precamini : deprecamini $P^{p c} M i \|$ flos : $\operatorname{ros} P \|$ iustitiam : i. et quaerite iustitiam $A$ \| quaerite mansuetudinem : et q. m. $A B \operatorname{Tr} W u$ quaerite mansuetudinem delendum esse coni. in app. Mi $\|$ ea : ei $M A B \operatorname{Tr} W u$ 
35. Item apud Zachariam (Za 1,3): Conuertimini ad me, et conuertar ad wos.

36. Item apud Oseae (Os 14, 2-3): Conuertere, Israel, ad Dominum Deum tuum, quoniam infurmatus es in iniquitatibus tuis. Assumite uobiscum multos et conuertimini ad Dominum Deum uestrum. Dicite ei adorantes: potens es dimittere peccata nostra, ut non accipiatis iniquitatem, sed ut accipiatis bona.

37. Item in Ecclesiastico (Si 17, 25.26-29 LXX): Conuertere ad Deum et relinque peccata tua et nimis odito execrationem et cognosce iustitias et iudicia Dei et sta in sorte propitiationis altissimi et uade in partem saeculi sancti cum uiuis et dantibus confessionem. Non demoreris in errore impiorum. A mortuo quasi nihil perit confessio. Viuus et sanus confiteberis Deo et gloriaberis in miserationibus illius, quoniam magna misericordia Dei et propitiatio illius conuertentibus ad se.

38. Item illic (Si 20, 4): Quam bonum est correptum manifestare paenitentiam! Sic enim effugies uoluntarium peccatum.

39. Item in Actibus apostolorum (Ac 8, 20-23): Ait autem ad illum Petrus: pecunia tua tecum sit in perditione, quoniam gratiam Dei putas te per pecuniam posse consequi. Non est tibi pars neque sors in hac fide, quia cor tuum non est rectum apud Dominum. Paenitentiam itaque age ab hac nequitia tua et precare Dominum, si forte remittatur tibi cogitatio cordis tui. In obligatione enim iniquitatis et amaritudine fellis uideo te esse.

40. Item in epistola beati Pauli ad Corinthios secunda $(2$ Co 7,10$)$ : Quae enim secundum Deum est tristitia, paenitentiam in salutem stabilem operatur; saeculi autem tristitia mortem operatur.

41. Item illic de hoc ipso (2 Co 2, 10-11): Si cui autem aliquid donastis, et ego; nam et ego quod donaui, propter uos in facie Christi, ut non circumueniamur a Satana, nec enim uersutias eius ignoramus.

35. et : et ego $P M i$

36. item : i. osee $A^{\text {ac }} \|$ apud : apud ad $P^{\text {ac }} \|$ in iniquitatibus : iniquitatibus $A B \operatorname{Tr} W u \|$ ut non : et non $P$

37. conuertere : conuerte $M \|$ deum : dominum $A B \operatorname{Tr} W u M i \|$ relinque : relique $M$ relinquere $A$ $\|$ odito GHP coni. Wu Mi : odite $M A B$ Tr $\|$ cognosce : cognose $M^{\text {ac }} \|$ in partem - cum $H^{\text {tas }} \|$ sancti om. $A B \operatorname{Tr} \|$ uiuis ; nimis $M \|$ demoreris ; dormieris $P$ demorieris $A B^{\mathrm{pc}} W u M i \quad$ derierit $B^{\text {ac }}$

38. correptum : correctum $A B$ cor rectum $\operatorname{Tr} \|$ paenitentiam : paenitentia $M \|$ effugies : effigies $A B$

39. tibi pars ... sors : pars ... sors tibi $M A B \operatorname{Tr} W_{u} \|$ fide : uita $B^{\text {ac }} \|$ non est ${ }^{2}$ : unde $M A B$ non $W_{u}$ $M i \|$ rectum : tectum $A B \|$ paenitentiam itaque : i. p. $A B \operatorname{Tr} W u \|$ uideo : in deo $M^{\text {pc }}$

40. beati pauli : pauli beati $A B$ pauli benedicti $\operatorname{Tr} \|$ secunda : secundam $M \|$ paenitentiam : paenitentia $M A\|\|$ stabilem operatur : o. stabile $M \quad$ o. in s. $A \quad$ o. stabulem $B \quad$ o. s. Tr Wu ll saeculi autem - operatur $P^{\text {mg }}$

41. de hoc ipso secl. Mi ll circumueniamur : cirueniamur $A$ 
42. Item illic ( 2 Co 12, 20.21): Timeo autem ne forte, cum uenero ad uos, iterum humiliet me Deus apud uos, et lugeam multos ex his qui ante peccauerunt et non egerunt paenitentiam super quae gesserunt, fornicationem et impudicitiam.

43. Item illic $(2$ Co 13, 2): Praedixi et praedico, ut praesens secundo et absens nunc his, qui ante peccauerunt, et ceteris omnibus, quia si uenero iterum, non parcam.

44. Item ad Timotheum secunda (2 Tm 2, 16-26): Profanas autem nouitates uocum deuita. Multum enim proficiunt ad impietatem; nam sermo eorum sicut cancer serpit, ex quibus est Hymenaeus et Filetus, qui a ueritate exciderunt, dicentes resurrectionem iam factam et quorumdam fidem subuertunt. Sed firmum fundamentum Dei stat, habens signaculum hoc: cognouit Deus qui sunt eius, et: discedat ab omni iniquitate omnis qui nominat nomen Domini. In magna autem domo non solum sunt uasa aurea et argentea, sed et lignea et fictilia, et quaedam quidem in honorem, quaedam autem in contumeliam. Si quis ergo emundauerit se $a b$ istis, erit uas in honore sanctificatum, et utile Domino, ad omne opus bonum paratum. Iuuenilia autem desideria fuge. Sectare uero iustitiam, fidem, caritatem, pacem cum his qui inuocant Dominum de corde puro. Stultas autem et sine disciplina quaestiones deuita, sciens quia generant lites. Seruum autem Domini non oportet litigare, sed mansuetum esse ad omnes, docibilem, patientem, cum modestia corripientem eos qui resistunt, ne quando det illis Deus paenitentiam ad cognoscendam ueritatem et resipiscant de diaboli laqueis, a quo capti tenentur, ad ipsius uoluntatem.

45. Item in Apocalipsi (Ap 2,5): Memento unde cecideris, et age paenitentiam; sin autem, ueniam tibi cito et candelabrum tuum de loco suo mouebo.

42. item illic om. $P \| \mathrm{cum}:$ quoniam $A\left\|\mathrm{me} P^{\mathrm{mg}}\right\| \mathrm{uos}^{2}$ om. $M A B \| \mathrm{l}$ his $:$ hiis $A W u$

43. secundo GHP coni. Wu $M i$ : sedero $M$ sedeo $A B$ Tr $\| \mathrm{et}^{2}$ : ut $P \|$ his : hiis $A B W_{u} \|$ ante : autem $M A B \|$ iterum : itenum $H^{\text {ac }}$ | parcam : peream $A B$

44. uocum : uotum $A \|$ sicut : sicer $A B \|$ hymenaeus : hymineus $M A B \|$ subuertunt : subuertit $M A B$ subuerterunt $W u \operatorname{Tr} M i \|$ fundamentum : firmamentum $P$ II discedat : discedet $\operatorname{Tr} \|$ omnis : omnes $A B \|$ nominat : nominant $A B \|$ lignea : ligna $B \|$ quidem : q. honore $A \|$ emundauerit $G H P M$ coni. in app. Tr $W u M i$ : emendauerit $A B$ Tr $\|$ erit : erat $B^{\text {ac }} \|$ in honore : ad honorem $A^{\text {ac }}$ in honorem $A^{\mathrm{pc}} B \operatorname{Tr} W u \|$ opus bonum : b. o. $A B$ Tr $W u l \|$ his : hiis $A W u \|$ inuocant : inuocat $P \|$ seruum autem : seruum $A W u \|$ modestia : molestia $A \|$ resipiscant : respiciant $A$

45. cecideris : excideris $P M i \|$ tuum om. $A B T r$

- GHMA explicit $P \quad$ finis est $B \quad$ finis $T r$ 